\title{
Carbon Dioxide-Water Emulsions for Enhanced Oil Recovery and Permanent Sequestration of Carbon Dioxide
}

\section{Final Technical Report}

August 6, 2013

\author{
University of Massachusetts Lowell \\ One University Avenue \\ Lowell, MA 01854 \\ DOE DE-FE0002691 \\ UML Project S51900000013066 \\ Award Date 01.15.2010 - 09.30.2011
}

\author{
David K. Ryan \\ Author \\ Dan S. Golomb \\ Co-Principal Investigator \\ Guang Shi, Cherry Shih \\ Postdoctoral Research Associates \\ Rob Lewczuk, Joshua Miksch, Rahul Manmode, Lin Li, \\ Srihariraju Mulagapati, Chetankumar Malepati \\ Graduate Research Associates
}




\section{DISCLAIMER -}

"This report was prepared as an account of work sponsored by an agency of the United States Government. Neither the United States Government nor any agency thereof, nor any of their employees, makes any warranty, express or implied, or assumes any legal liability or responsibility for the accuracy, completeness, or usefulness of any information, apparatus, product, or process disclosed, or represents that its use would not infringe privately owned rights. Reference herein to any specific commercial product, process, or service by trade name, trademark, manufacturer, or otherwise does not necessarily constitute or imply its endorsement, recommendation, or favoring by the United States Government or any agency thereof. The views and opinions of authors expressed herein do not necessarily state or reflect those of the United States Government or any agency thereof." 


\section{Abstract}

This project involves the use of an innovative new invention - Particle Stabilized Emulsions (PSEs) of Carbon Dioxide-in-Water and Water-in-Carbon Dioxide for Enhanced Oil Recovery (EOR) and Permanent Sequestration of Carbon Dioxide. The EOR emulsion would be injected into a semi-depleted oil reservoir such as Dover 33 in Otsego County, Michigan. It is expected that the emulsion would dislocate the stranded heavy crude oil from the rock granule surfaces, reduce its viscosity, and increase its mobility. The advancing emulsion front should provide viscosity control which drives the reduced-viscosity oil toward the production wells. The make-up of the emulsion would be subsequently changed so it interacts with the surrounding rock minerals in order to enhance mineralization, thereby providing permanent sequestration of the injected $\mathrm{CO}_{2}$.

In Phase 1 of the project, the following tasks were accomplished:

1. Perform laboratory scale $(\mathrm{mL} / \mathrm{min})$ refinements on existing procedures for producing liquid carbon dioxide-in-water $(\mathrm{C} / \mathrm{W})$ and water-in-liquid carbon dioxide (W/C) emulsion stabilized by hydrophilic and hydrophobic fine particles, respectively, using a Kenics-type static mixer.

2. Design and cost evaluate scaled up (gal/min) $\mathrm{C} / \mathrm{W}$ and $\mathrm{W} / \mathrm{C}$ emulsification systems to be deployed in Phase 2 at the Otsego County semi-depleted oil field.

3. Design the modifications necessary to the present $\mathrm{CO}_{2}$ flooding system at Otsego County for emulsion injection.

4. Design monitoring and verification systems to be deployed in Phase 2 for measuring potential leakage of $\mathrm{CO}_{2}$ after emulsion injection.

5. Design production protocol to assess enhanced oil recovery with emulsion injection compared to present recovery with neat $\mathrm{CO}_{2}$ flooding.

6. Obtain Federal and State permits for emulsion injection.

Initial research focused on creating particle stabilized emulsions with the smallest possible globule size so that the emulsion can penetrate even low-permeability crude oilcontaining formations or saline aquifers. The term "globule" refers to the water or liquid carbon dioxide droplets sheathed with ultrafine particles dispersed in the continuous external medium, liquid $\mathrm{CO}_{2}$ or $\mathrm{H}_{2} \mathrm{O}$, respectively. The key to obtaining very small globules is the shear force acting on the two intermixing fluids, and the use of ultrafine stabilizing particles or nanoparticles. We found that using Kenics-type static mixers with a shear rate in the range of 2700 to $9800 \mathrm{~s}^{-1}$ and nanoparticles between 100-300 nm produced globule sizes in the 10 to $20 \mu \mathrm{m}$ range. Particle stabilized emulsions with that kind of globule size should easily penetrate oil-bearing formations or saline aquifers where the pore and throat size can be on the order of $50 \mu \mathrm{m}$ or larger.

Subsequent research focused on creating particle stabilized emulsions that are deemed particularly suitable for Permanent Sequestration of Carbon Dioxide. Based on a survey of the literature an emulsion consisting of $70 \%$ by volume of water, $30 \%$ by volume of liquid or supercritical carbon dioxide, and $2 \%$ by weight of finely pulverized limestone $\left(\mathrm{CaCO}_{3}\right)$ was selected as the most promising agent for permanent sequestration of $\mathrm{CO}_{2}$. In order to assure penetration of the emulsion into tight formations of sandstone or other silicate rocks and carbonate or dolomite rock, it is necessary to use an emulsion consisting of the smallest possible globule size. In previous reports we described a high shear static mixer that can create such small globules. In addition to the high shear mixer, 
it is also necessary that the emulsion stabilizing particles be in the submicron size, preferably in the range of 0.1 to $0.2 \mu \mathrm{m}$ (100 to $200 \mathrm{~nm}$ ) size. We found a commercial source of such pulverized limestone particles, in addition we purchased under this DOE Project a particle grinding apparatus that can provide particles in the desired size range. Additional work focused on attempts to generate particle stabilized emulsions with a flow through, static mixer based apparatus under a variety of conditions that are suitable for permanent sequestration of carbon dioxide. A variety of mixtures of water, $\mathrm{CO}_{2}$ and particles may also provide suitable emulsions capable of PS. In addition, it is necessary to test the robustness of PSE formation as composition changes to be certain that emulsions of appropriate size and stability form under conditions that might vary during actual large scale EOR and sequestration operations.

The goal was to lay the groundwork for an apparatus and formulation that would produce homogenous microemulsions of $\mathrm{CO}_{2}$-in-water capable of readily mixing with the waters of deep saline aquifers and allow a safer and more permanent sequestration of carbon dioxide. In addition, as a beneficial use, we hoped to produce homogenous microemulsions of water-in- $\mathrm{CO}_{2}$ capable of readily mixing with pure liquid or supercritical $\mathrm{CO}_{2}$ for use in Enhanced Oil Recovery (EOR). However, true homogeneous microemulsions have proven very difficult to produce and efforts have not yielded either a formulation or a mixing strategy that gives emulsions that do not settle out or that can be diluted with the continuous phase in varying proportions.

Other mixtures of water, $\mathrm{CO}_{2}$ and particles, that are not technically homogeneous microemulsions, may also provide suitable emulsions capable of PS and EOR. For example, a homogeneous emulsion that is not a microemulsion might also provide all of the necessary characteristics desired. These characteristics would include easy formation, stability over time, appropriate size and the potential for mineralization under conditions that would be encountered under actual large scale sequestration operations. This report also describes work with surrogate systems in order to test conditions and 


\section{TABLE OF CONTENTS}

INTRODUCTION AND SUMMARY $\quad 6$

LABORATORY SCALE EMULSION FORMATION

1.1 RESULTS OF EMULSION FORMATION

SCALED-UP EMULSIFICATION SYSTEM

MODIFICATIONS TO THE CO2 FLOODING SYSTEM FOR EMULSION INJECTION 9

MONITORING, VERIFICATION AND ACCOUNTING PLAN (MVA) 10

AIR MONITORING

PERFluOROCARbon TRacer (PFTs) 11

CHEMICAL MEASURMENTS IN PRODUCED FLUIDS

NEAR SURFACE GROUNDWATER MONITORING

4.1 - EOR TARGET MVA PLAN

4.1.1 PRE-INJECTION PHASE

4.1.2 OPERATING PHASE PLAN

4.1.3 CLOSURE PHASE $\quad 19$

4.1.4 POST-ClOSURE PHASE

ASSESSMENT OF EMULSION-EOR OIL PRODUCTION

OBTAIN FEDERAL AND STATE PERMITS FOR EMULSION INJECTION 20

PARTICLE STABILIZED EMULSIONS BACKGROUND $\quad 20$

EMULSION FORMATION APPARATUS

RESULTS OF PSE FORMATION

PACKING DENSITY $\quad 22$

PRELIMINARY CONCLUSIONS $\quad 23$

EMULSION FORMATION APPARATUS

Results OF The Static MiXer Performance 25

TABLE $1 . \quad 26$

TABLE 2.

DESIGN OF SCALED-UP EMULSION FORMING APPARATUS FOR FIELD TESTING 26

STATIC MiXER THEORY $\quad 26$

TABLE 3: $\quad 28$

TABLE 4: $\quad 29$

STATIC Mixer ConClusions $\quad 29$

PERMANENT SEQUeSTRATION OF $\mathrm{CO}_{2}$

$\mathrm{CO}_{2}-\mathrm{H}_{2} \mathrm{O}$ EMULSION

EXPERIMENTAL

19. 1 MATERIALS $\quad 31$

19. 2 MIXING APPARATUS

FLOW REACTOR RESULTS

ECONOMICS $\quad 32$

FLOW Through EMULSION PRODUCTION

CONCLUSIONS

REFERENCES

LIST OF FIGURES

$\begin{array}{ll}\text { LIST OF TABLES } & 35\end{array}$ 


\section{Introduction and Summary}

This project was awarded in response to DOE/NETL solicitation DE-FOA-0000015

Carbon Capture and Sequestration from Industrial Sources and Innovative Concepts for Beneficial $\mathrm{CO}_{2}$ Use, Technology Area 2 - Innovative Concepts for Beneficial $\mathrm{CO}_{2}$ Use.

The project centers on using our invention - Particle Stabilized Emulsions (PSEs) of Carbon Dioxide-in-Water and Water-in-Carbon Dioxide for Enhanced Oil Recovery (EOR) and Permanent Sequestration of Carbon Dioxide. The EOR emulsion would be injected into a semi-depleted oil reservoir such as Dover 33 in Otsego County, Michigan. It is expected that the emulsion would dislocate the stranded heavy crude oil from the rock granule surfaces, reduce its viscosity, and increase its mobility. The advancing emulsion front should provide viscosity control which drives the reduced-viscosity oil toward the production wells. The make-up of the emulsion would be subsequently changed so it interacts with the surrounding rock minerals in order to enhance mineralization, thereby providing permanent sequestration of the injected $\mathrm{CO}_{2}$. In Phase 1 of the project, the following tasks were accomplished:

1. Perform laboratory scale $(\mathrm{mL} / \mathrm{min})$ refinements on existing procedures for producing liquid carbon dioxide-in-water $(\mathrm{C} / \mathrm{W})$ and water-in-liquid carbon dioxide $(\mathrm{W} / \mathrm{C})$ emulsion stabilized by hydrophilic and hydrophobic fine particles, respectively, using a Kenics-type static mixer.

2. Design and cost evaluate scaled up (gal/min) $\mathrm{C} / \mathrm{W}$ and $\mathrm{W} / \mathrm{C}$ emulsification systems to be deployed in Phase 2 at the Otsego County semi-depleted oil field.

3. Design the modifications necessary to the present $\mathrm{CO}_{2}$ flooding system at Otsego County for emulsion injection.

4. Design monitoring and verification systems to be deployed in Phase 2 for measuring potential leakage of $\mathrm{CO}_{2}$ after emulsion injection.

5. Design production protocol to assess enhanced oil recovery with emulsion injection compared to present recovery with neat $\mathrm{CO}_{2}$ flooding.

6. Obtain Federal and State permits for emulsion injection.

Our initial research focused on creating particle stabilized emulsions with the smallest possible globule size so that the emulsion can penetrate even low-permeability crude oilcontaining formations or saline aquifers. The term "globule" refers to the water or liquid carbon dioxide droplets sheathed with ultrafine particles dispersed in the continuous external medium, liquid $\mathrm{CO}_{2}$ or $\mathrm{H}_{2} \mathrm{O}$, respectively. The key to obtaining very small globules is the shear force acting on the two intermixing fluids, and the use of ultrafine stabilizing particles or nanoparticles. We found that using Kenics-type static mixers with a shear rate in the range of 2700 to $9800 \mathrm{~s}^{-1}$ and nanoparticles between 100-300 nm produced globule sizes in the 10 to $20 \mu \mathrm{m}$ range. Particle stabilized emulsions with that kind of globule size should easily penetrate oil-bearing formations or saline aquifers where the pore and throat size can be on the order of $50 \mu \mathrm{m}$ or larger (Wardlaw et al., 1987).

Subsequent research focused on creating particle stabilized emulsions that are deemed particularly suitable for Permanent Sequestration of Carbon Dioxide. Based on a survey of the literature (see below) we selected an emulsion consisting of $70 \%$ by volume of water, $30 \%$ by volume of liquid or supercritical carbon dioxide, and $2 \%$ by weight of finely pulverized limestone $\left(\mathrm{CaCO}_{3}\right)$ as the most promising agent for permanent 
sequestration of $\mathrm{CO}_{2}$. In order to assure penetration of the emulsion into tight formations of sandstone or other silicate rocks and carbonate or dolomite rock, it is necessary to use an emulsion consisting of the smallest possible globule size. In previous reports we described a high shear static mixer that can create such small globules. In addition to the high shear mixer, it is also necessary that the emulsion stabilizing particles be in the submicron size, preferably in the range of 0.1 to $0.2 \mu \mathrm{m}$ (100 to $200 \mathrm{~nm})$ size. We found a commercial source of such pulverized limestone particles, in addition we purchased under this DOE Project a particle grinding apparatus that can provide particles in the desired size range.

Additional work focused on attempts to generate particle stabilized emulsions with our flow through, static mixer based apparatus under a variety of conditions that are suitable for permanent sequestration of carbon dioxide. A variety of mixtures of water, $\mathrm{CO}_{2}$ and particles may also provide suitable emulsions capable of PS. In addition, it is necessary to test the robustness of PSE formation as composition changes to be certain that emulsions of appropriate size and stability form under conditions that might vary during actual large scale EOR and sequestration operations.

Our goal was to lay the groundwork for an apparatus and formulation that would produce homogenous microemulsions of $\mathrm{CO}_{2}$-in-water capable of readily mixing with the waters of deep saline aquifers and allow a safer and more permanent sequestration of carbon dioxide. In addition, as a beneficial use, we hoped to produce a homogenous microemulsions of water-in- $\mathrm{CO}_{2}$ capable of readily mixing with pure liquid or supercritical $\mathrm{CO}_{2}$ for use in Enhanced Oil Recovery (EOR). However, true homogeneous microemulsions have proven very difficult to produce and our efforts have not yielded either a formulation or a mixing strategy that gives emulsions that do not settle out or that can be diluted with the continuous phase in varying proportions.

Other mixtures of water, $\mathrm{CO}_{2}$ and particles, that are not technically homogeneous microemulsions, may also provide suitable emulsions capable of PS and EOR. For example, a homogeneous emulsion that is not a microemulsion might also provide all of the necessary characteristics desired. These characteristics would include easy formation, stability over time, appropriate size and the potential for mineralization under conditions that would be encountered under actual large scale sequestration operations. We also worked with surrogate systems, as we have done in the past, in order to test conditions and perfect techniques that would lead to successful emulsion formation.

\section{Laboratory Scale Emulsion Formation.}

A Particle Stabilized Emulsion (PSE) formation apparatus was constructed, functionally tested, and emulsion formation has been demonstrated. The system is depicted in Figure 1. The heart of the system is a Kenics type static mixer. This is a stainless steel tube of preselected diameter with curved baffles (see Figure 2). With high flow rates and initial large pressure (high Reynolds numbers), the flow in the static mixer is highly turbulent. Under those conditions, the ingredients flowing into the static mixer are thoroughly dispersed. The higher the shear force, i.e. pressure and flow rate, the better the mixing and the dispersion of one fluid into another. We selected the static mixer as the dispersion agent because it produces a continuous flow, rather than a batch reactor with mechanical mixing, which would have to be reloaded with fresh ingredients after discharge. Furthermore, the static mixer is commercially available from $\mathrm{mL} / \mathrm{min}$ to gal $/ \mathrm{min}$ flow 
rates. Also, if necessary, the mixing can be further augmented by using a flow-through sonicator upstream of the static mixer.

In general, two types of PSE emulsions will be formed with the static mixer: (1) Water-in-Carbon Dioxide (W/C), and (2) Carbon Dioxide-in-Water (C/W). W/C emulsions are obtained with hydrophobic particles; $\mathrm{C} / \mathrm{W}$ emulsions are obtained with hydrophilic particles (Golomb et al., 2006). The static mixer is fed with three types of fluids: (1) liquid or supercritical carbon dioxide; (2) water; (3) a slurry of ultrafine particles in water or ethanol. The proportions of water/carbon dioxide is varied according to needs. For enhanced oil recovery, the proportions are usually $70 \%$ by volume $\mathrm{CO}_{2}$, $30 \%$ by volume $\mathrm{H}_{2} \mathrm{O}$. For permanent $\mathrm{CO}_{2}$ sequestration the proportions are usually inverted, a higher percentage of $\mathrm{H}_{2} \mathrm{O}$, and a smaller percentage of $\mathrm{CO}_{2}$. A heating or cooling bath around the inlet and around the static mixer allows to form an emulsion with liquid or supercritical $\mathrm{CO}_{2}$, respectively. The critical constants of $\mathrm{CO}_{2}$ are $\mathrm{T}_{\mathrm{c}}=31^{\circ} \mathrm{C}$ $\left(88^{\circ} \mathrm{F}\right), \mathrm{p}_{\mathrm{c}}=7.3 \mathrm{MPa}(1073 \mathrm{psi})$. Because it is difficult to obtain a homogeneous slurry of particles in water (particles tend to agglomorate, i.e. form clumps), a separate concentrated slurry of particles is obtained in a stirred container, sometime with the aid of a surfactant, or in a different medium than water, e.g. ethanol. The three fluids are fed into three separate syringe-type pumps (Teledyne ISCO A1000 continuous flow syringe pump for $\mathrm{CO}_{2}$, and 500D for water and slurry). The three syringe pumps deliver their content at equal pressure, $2000 \mathrm{psi}$, to the static mixer at a preselected flow rate, such as to obtain the desired proportions of $\mathrm{CO}_{2}$ and $\mathrm{H}_{2} \mathrm{O}$ in the ensuing emulsion, respectively. Normally, but not always, the amount of particles is selected to obtain a $2 \%$ by weight of particles in the final emulsion.

The formed emulsion flows through a heated tube (to avoid flashing of the liquid $\mathrm{CO}_{2}$ into vapor) into a pressure view cell (Figure 3). The view cell is equipped with two $1 / 2$ inch thick tempered glass, 1 inch diameter, on each side. One window allows illumination, the other photography or microscopy of the emulsion that flows through the view cell. From the view cell, across a back-pressure regulator, the emulsion flows into a ventilated hood. There the $\mathrm{CO}_{2}$ flashes into vapor, and is exhausted into the atmosphere. The remaining water slurry is dumped into a sink. The emulsion contains no toxic materials.

\subsection{Results of Emulsion Formation}

For the initial laboratory experiments, we used a $1 / 4$ inch OD, 11 inch long static mixer. First we simply dispersed water in supercritical carbon dioxide without adding emulsionstabilizing particles. We mixed $90 \%$ by volume $\mathrm{CO}_{2}$ with $10 \%$ by volume $\mathrm{H}_{2} \mathrm{O}$. Inlet pressure to the static mixer $1250 \mathrm{psi}$, temperature $35^{\circ} \mathrm{C}$. Thus, $\mathrm{CO}_{2}$ is in the supercritical state. Figure 4 shows a photo of the dispersion in the pressure view cell. Tiny water droplets are dispersed in carbon dioxide. The mean water droplet size is in the range of $20-30 \mu \mathrm{m}$. Such a dispersion is not stable; a phase separation usually occurs within seconds, with a sharp meniscus between the two liquids, $\mathrm{CO}_{2}$ and water.

Next, we mixed $70 \%$ by volume $\mathrm{CO}_{2}, 30 \%$ by volume slurry of pulverized Teflon in water containing $0.6 \%$ by volume Triton X-100 surfactant. The amount of Teflon in the slurry was calculated to produce a final emulsion with $2 \%$ by weight of Teflon. The mean particle size of Teflon is $3 \mu \mathrm{m}$. The sole reason of using pulverized Teflon in these initial experiments is that Teflon is white, and allows easy visualization and photography 
of the ensuing emulsion. Furthermore, the apparatus can be easily cleaned after every run. The inlet to the static mixer, as well as the mixer, was heated to $35{ }^{\circ} \mathrm{C}$, so that the $\mathrm{CO}_{2}$ is in a supercritical state. The resulting emulsion is shown in the photo of Figure 5. Tiny water droplets sheathed with a layer of pulverized Teflon particles - called globules - are dispersed in supercritical $\mathrm{CO}_{2}$. The diameter of the globules is in the range $50-80 \mu \mathrm{m}$. The emulsion appears to be stable, there was no visible phase separation within the view cell.

Subsequently, we mixed $70 \%$ by volume $\mathrm{CO}_{2}, 30 \%$ by volume of a slurry of carbon black particles in water, calculated to obtain a final mix containing $2 \%$ by weight carbon black. The slurry was made up by diluting with pure water a commercial product (Solution Dispersions, Inc.) containing $50 \%$ by weight carbon black particles, mean size $0.2-0.3 \mu \mathrm{m}$. The commercial slurry contains an unknown "anionic" stabilizer in order to prevent carbon black particles from clustering. Inlet pressure to the static mixer $1250 \mathrm{psi}$, temperature $35{ }^{\circ} \mathrm{C}$. Thus $\mathrm{CO}_{2}$ is in the supercritical state. The view in the pressure cell was completely black, so we could not determine globule size. In the future, we have to construct a pressure cell with windows very closely spaced, so that the optical path is on the order of a few $\mathrm{mm}$, thus enabling to photograph individual globules. In previous laboratory experiments, we used a microfluidizer to form an emulsion of water-indodecane stabilized by carbon black particles. Dodecane was used as a surrogate for $\mathrm{CO}_{2}$, so that the observations could be rendered in glass vessels at atmospheric pressure. The emulsion consisted of $70 \%$ by volume dodecane (the external phase), and $30 \%$ by volume water (the internal, dispersed phase), and $2 \%$ by weight of carbon black particles (mean diameter $0.2-0.3 \mu \mathrm{m}$ ). The resulting globules consisted of water droplets sheathed with a layer of carbon black particles dispersed in dodecane. The diameter of the globules was in the range $5-10 \mu \mathrm{m}$ (see Figure 6). It is very likely that the static mixer produced globules in a similar or even smaller size range, considering that the $\mathrm{CO}_{2}$ was in a supercritical state, which generally produces smaller globules (Golomb et al, 2006).

\section{Scaled-up Emulsification System}

Design work on scaled-up emulsion forming equipment was then conducted. Two complementary devices were investigated in this regard, a Kenics type static mixer and a Sonolator by Sonic Mixing. A preliminary schematic diagram is shown in Figure 7. In this figure both devices are shown. Our experience with the static mixer has demonstrated its characteristics and capabilities. It is a simple device that can generate significant shear force and form emulsions easily at the laboratory scale. Scaled-up versions have been used in many industrial applications with great success, but not in the particular application being proposed here. As a backup plan, we also extensively investigated the specifications and performance characteristics of the Sonolator.

\section{Modifications to the $\mathrm{CO}_{2}$ Flooding System for Emulsion Injection}

The emulsion forming equipment is designed to be delivered on a pad and positioned adjacent to the $\mathrm{CO}_{2}$ supply pipeline for the Dover 33 site (see section 2 above). Connections would be made and valves installed to allow emulsion supply to be gradually increased augmenting the flow of $\mathrm{CO}_{2}$. Because the initial emulsion would be an EOR emulsion, it is of the W/C type which has $\mathrm{CO}_{2}$ as the continuous phase and 
therefore is completely miscible with pure $\mathrm{CO}_{2}$. Introduction of the emulsion should be much like mixing two $\mathrm{CO}_{2}$ streams together.

\section{Monitoring, Verification and Accounting Plan (MVA)}

An integral part of the Phase 2 project preparations was a Monitoring, Verification and Accounting Plan (MVA) with three primary goals:

1) monitor the site for possible leaks that could affect human health and safety as well as pose environmental problems short or long-term

2) verify the sequestration of $\mathrm{CO}_{2}$ by making measurements of the chemistry in the system and evaluating emulsion performance and progress

3 ) determine the amount of $\mathrm{CO}_{2}$ sequestered and estimate the future potential for sequestration under the conditions being tested.

The MVA plan was designed with several generic aspects, but also contained many site specific features necessary because the unique geology of the Michigan pinnacle reefs presents certain very important advantages over other EOR and sequestration candidates. For example, decades of $\mathrm{CO}_{2} \mathrm{EOR}$ in the Michigan reefs and at the proposed site have been conducted without serious incident and therefore greatly reduce the uncertainty typically encountered in $\mathrm{CO}_{2}$ sequestration projects. It is interesting to note that some reef structures in the region have been utilized for natural gas storage for many years without creating unacceptable risks or problems. Therefore, the "closed container" nature of the reef system lends itself to long-term $\mathrm{CO}_{2}$ sequestration with a very low possibility of leaks. Additionally, oil bearing strata in the Michigan pinnacle reef system is found at depths which often exceed 5,000 feet, even deeper than deep saline aquifers that are typical candidates for $\mathrm{CO}_{2}$ sequestration (Figure 8). Any $\mathrm{CO}_{2}$ that might possibly leak from these depth would likely be trapped in other layers and never reach the surface. Finally a very low number of penetrations have been made and are typically made in the reefs for oil production. This factor greatly reduces the possibility of leaks through manmade perforations and limits the number of potential monitoring sites for leak detection. All of these above mentioned factors were important considerations in the development of a site specific MVA plan.

The MVA plan developrd has four aspects that work together to achieve the overall MVA goals and objectives. These include:

1) a network of surface level $\mathrm{CO}_{2}$ air monitoring stations to continuously monitor ground level atmospheric levels of $\mathrm{CO}_{2}$ throughout the entire project commencing prior to injection of $\mathrm{CO}_{2}$

2) tracer studies utilizing a suite of highly detectable perfluorocarbon tracers (PFT's) for in-hole measurement of $\mathrm{CO}_{2}$ movement and for surface monitoring of potential leaks

3) chemical measurements of produced fluids for $\mathrm{pH}$, alkalinity, carbonate chemistry, total dissolved solids (TDS), calcium concentrations and other major cations and anions to thoroughly characterize sequestration and mineralization reactions 
4) system control measurements of $\mathrm{CO}_{2}$ volume, flow rate, injectivity and related parameters that will provide detailed information on the response of the reservoir to the injection of $\mathrm{CO}_{2}$ and emulsions.

\section{Air Monitoring of $\mathrm{CO}_{2}$}

Air monitoring for $\mathrm{CO}_{2}$ was planned to be accomplished with a network of wireless sensors placed at key locations around the site. A minimum of 5 monitoring stations could be established including the injection well, the location of the two production wellheads and adjacent to abandon (i.e. plugged wells) and dry holes on the site. Monitors could be mounted on poles approximately 8 to 10 feet above the ground with rechargeable batteries and solar panels. A unit such as the eKo model EK2120 Outdoor Long Range Wireless Monitoring System (Crossbow Technology, Milpitas, CA) or other commercially available system would be used to provide continuous monitoring of $\mathrm{CO}_{2}$ levels for the 36 month project period. Monitors would be installed at the very beginning of the project by a subcontractor (Field Monitoring Services, Woburn, MA) that has extensive experience in remote data collection and handling. Routine maintenance and repair or replacement would also be conducted to ensure continuous operation. Data would be transmitted wirelessly to a node with data logging capabilities and internet connectivity. Information about $\mathrm{CO}_{2}$ levels would be available to authorized project personnel via a secure website. Any anomalies in the background data would trigger a response to ensure the complete safety of $\mathrm{CO}_{2}$ and emulsion injection operations.

\section{Perfluorocarbon Tracers (PFTs)}

The use of perfluorocarbon tracers for $\mathrm{CO}_{2}$ sequestration operations has become state-of-the-art technology in recent years. Work by Strazisar et al. (2009) and Wells et al. (2007) has demonstrated its utility particularly for surface monitoring. Two aspects of the MVA plan could be covered by PFTs, surface leak monitoring and subsurface $\mathrm{CO}_{2}$ movement and flow.

PFTs are a group of completely fluorinated cycloalkane compounds that are extremely stable to degradation in the environment and can be detected at femtogram levels (i.e. $10^{-15} \mathrm{~g}$ ) by capillary gas chromatography (GC) with electron capture detection (ECD). Several of these compounds have been routinely used as tracers since about the 1980's when it was discovered that low levels in the environment coupled with exceptional detectability make them ideal tracers in several applications. In the proposed application, PFTs could be injected with $\mathrm{CO}_{2}$ at three separate times during the EOR and sequestration stages of a field project. Quantities in the range of $2 \mathrm{~g} /$ day would be introduced into the injection well using a $\mathrm{CO}_{2}$ cylinder premixed with PFTs.

Surface leak monitoring would be accomplished using passive capillary adsorption tube samplers (CATS) at 5 locations adjacent to those described above. Samplers should be deployed in duplicate and collected monthly during the 36 month project. At the laboratory, thermal desorption and analysis by GC with electron capture detection (ECD) would be used for analysis. Because of the extremely low detection limits of GC ECD for PFTs, trace level detection of possible $\mathrm{CO}_{2}$ leaks can be monitored effectively in this way. Pairs of different PFTs could be injected for each tracer event insuring that no carry over or cross contamination would occur in the system. Regular 
sampling of produced fluids would allow measurements of the $\mathrm{CO}_{2}$ and emulsion fronts as they passed through the reservoir. Dilution of the tracer would be anticipated to occur by a factor of $10^{8}$ resulting in easily detectable quantities.

\section{Chemical Measurements in Produced Fluids}

During $\mathrm{CO}_{2}$ injection operations samples of produced fluids would be collected from the production well at weekly intervals. Produced water would be subjected to rigorous analytical testing in order to understand the processes occurring in the reservoir. Tests would include, but not be limited to: $\mathrm{pH}$, conductivity, total dissolved solids (TDS), alkalinity, silicates, major anions, calcium, magnesium and other major cations. One of the most important goals would be to define the carbonate equilibrium $\left(\mathrm{HCO}_{3}{ }^{-}, \mathrm{CO}_{3}{ }^{2-}\right.$, $\mathrm{H}_{2} \mathrm{CO}_{3}$ ) and monitor changes that occur as $\mathrm{CO}_{2}$ is injected.

During EOR operations, baseline data would be generated that would characterize the reservoir system. Once the EOR stage is finished and sequestration begins, one of the primary mechanisms for retaining $\mathrm{CO}_{2}$ in the reservoir is expected to be solubility trapping. Here $\mathrm{CO}_{2}$ is chemically transformed from liquid or supercritical $\mathrm{CO} 2$ to a soluble carbonate species by dissolution of $\mathrm{CO}_{2}$ first as $\mathrm{H}_{2} \mathrm{CO}_{3}$, then as $\mathrm{HCO}_{3}{ }^{-}$. Two key reactions are involved

$$
\begin{aligned}
& \text { 1) } \mathrm{CO}_{2}+\mathrm{H}_{2} \mathrm{O} \leftarrow \rightarrow \mathrm{H}_{2} \mathrm{CO}_{3} \text { (carbonic acid) } \\
& \text { 2) } \mathrm{H}_{2} \mathrm{CO}_{3}+\mathrm{CaCO}_{3} \leftarrow \rightarrow 2 \mathrm{HCO}_{3}^{-}+\mathrm{Ca}^{2+}
\end{aligned}
$$

In reaction $1, \mathrm{CO}_{2}$ reacts with water to form carbonic acid. Water is one component of the emulsion system being studied and would be in intimate contact with the $\mathrm{CO}_{2}$. This equilibrium reaction is rather fast and is facilitated by the fact that emulsions consist of dispersed fluids where a very large interface exists between the two fluids. The large interface allows more dissolution to occur in a shorter time. In addition to the water present as part of the emulsion, water is also present in the formation to provide greater volumes for solubility trapping.

Reaction 2 occurs in two major ways. First the sequestration emulsion is prepared with very fine, nanoparticulate calcite $\left(\mathrm{CaCO}_{3}\right)$ which is the stabilizing particle for this PSE or Pickering type emulsion. This calcite resides at the $\mathrm{CO}_{2} / \mathrm{H}_{2} \mathrm{O}$ interface perfectly positioned for participation in reaction 2. Second, the pinnacle reef system is composed of the mineral dolomite which reacts in exactly the same way producing $\mathrm{HCO}_{3}{ }^{-}$. More than ample carbonate is available in the system to completely react and neutralize carbonic acid produced from $\mathrm{CO}_{2}$ and $\mathrm{H}_{2} \mathrm{O}$. Additionally, the reaction of carbonic acid with the dolomite of the reef has the added benefit of gradually opening more pore space within the reservoir.

\section{Near Surface Groundwater Monitoring}

Groundwater wells that currently exist at random locations in the vicinity the site would be routinely sampled and the water subjected to the same battery of tests described in the previous section. These wells are used for drinking water in some cases and site water in other cases and are fairly shallow, typically only a few hundred feet deep. Data 
collected would be scrutinized for any minor changes in groundwater chemistry that might occur in the very unlikely event of $\mathrm{CO}_{2}$ leakage or seepage from greater depths.

Any signs of leakage in air or water samples would trigger a cessation of $\mathrm{CO}_{2}$ injection operations and the commencement of mitigation measures.

As a part of utilizing the targeted EOR field in the project during the demonstration, the following work was designed to be implemented during Phases 2 of the demonstration:

\section{1 - EOR Target MVA Plan:}

Core Energy operates seven fields at various stages of $\mathrm{CO}_{2}$ flooding development, has a plan to add more fields, and owns significant EOR infrastructure in the project area that could have been made available to support a successful demonstration of the DOE UMEP. If a Phase 2 Grant was awarded the single most significant supplemental need required to execute the project would involve the expansion of compression capacity at Core Energy's $\mathrm{CO}_{2}$ capture, compression and drying facility.

Therefore, in developing this MVA Plan, especially the budgetary aspects; the partially depleted EOR target planned to be utilized was the Dover 33 Field, which consists of three wells.

4.1.1 Pre-injection Phase (initial design, establish baseline conditions, geological characterization, identify risks):

\section{Technologies/Activities during the pre-injection phase of the demonstration included:}

- 3-D Seismic Survey over the targeted field - For Phase 2, Core Energy prepared to share its 3-D seismic survey over the Dover 33 Field. A 3-D seismic survey is the only tool available for accurately mapping the size, shape and boundaries of Niagaran pinnacle reefs - the targeted EOR formation for the demonstration.

Accurately knowing this information serves multiple purposes related to volumetric estimates of reserves, reservoir modeling and simulation, well placement /utilization, and meeting regulatory requirements (e.g. unitization).

A 3-D seismic survey is conducted by laying out a grid pattern over the subject area to strategically locate source points and receivers. The source used for the subject surveys was small dynamite charges, approximately $1 / 3-1 / 2 \mathrm{lbs}$, buried in small diameter boreholes drilled to a depth of approximately 5 ' -10 '.

The seismic waves generated by the dynamite source points propagate through the various layers of rock at various speeds based on the properties of the rock and fluids contained within them, thus, allowing the underground formations to be accurately mapped. 
Only in the very immediate proximity of the source points is any noise and/or minute ground movement observed. Essentially, the output from the source points is undetectable and the shooting of the seismic surveys has very little to no impact on the surrounding area.
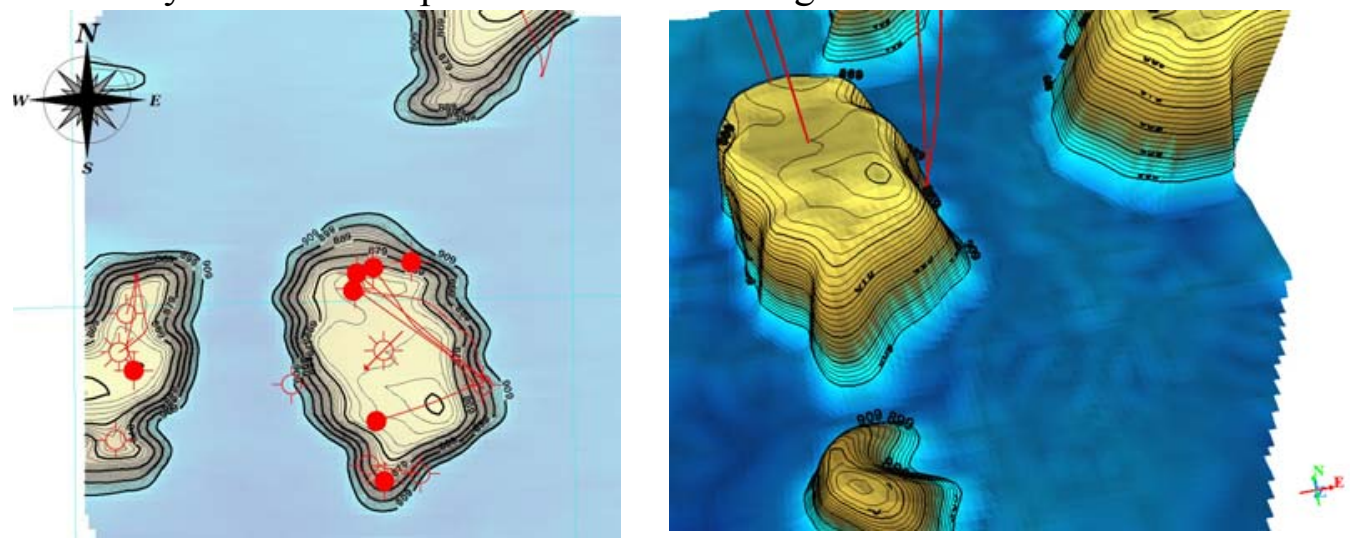

3-D seismic survey depiction of the Dover 33 Field, the EOR target field for the project.

- Conducting a field review and history of development for the field For the planned Phase 2, information available from Core Energy's files, the State of Michigan records and/or other sources, could have been reviewed, updated, and used to develop a complete history of development and production for the field.

- Wellbore inventory of all wells in the area of review (AoR) based on available data (using EPA UIC Class II Well criteria) - Planned for Phase 2, all wellbores in the AoR would have been inventoried to reassess the adequacy of their condition by ensuring that they have been constructed in a manner that meets the criteria of their EPA UIC Class II Injection Permit (i.e. the class of permit that regulates the injection for $\mathrm{CO}_{2}$ EOR projects). A remedial action plan would be developed and implemented for all wellbores that do not meet the subject criteria, to ensure that the Class II permit could be secured.

Core Energy holds three active EPA UIC permits, one for each of the wells in the Dover 33 Field, which was a huge plus for the demonstration as it removed the need to go through the lengthy, rigorous, and expensive permitting process.

Again, because the Niagaran pinnacle reefs being targeted for EOR are known to be superb containers for holding buoyant fluids over geologic time, the focus of the MVA plan was on wellbores - the most likely leakage pathway.

- Review of logs in the field and preparing necessary cross-sections, maps, etc. - During Phase 2, available well logs would have been 
reviewed to help characterize the geology and reservoir of the EOR target. As needed to aid in the project, the logs would be placed into a crosssection for use and reference.

- Calculating a material balance for all fluids/gases withdrawn from the field - Planned for Phase 2, the reservoir voidage (i.e. volume in reservoir barrels) of the withdrawn fluids/gas from primary production and first round of $\mathrm{CO}_{2}$ flooding would be calculated to allow for a determination of the volume of $\mathrm{CO}_{2}$ necessary for initial fill-up prior to establishing production.

- Identifying necessary permits - During Phase 1, UMass learned that Core Energy already has the permits necessary for operating an EOR project, which added significant value to the project and increased the certainty that a successful demonstration could be implemented in the desired time frame.

- Measuring current reservoir pressure - Planned for Phase 2, prereflood reservoir pressure would be measured using downhole pressure gauges. The pre-reflood pressure can then be compared with pressures taken at later times in the evolution of a flood to depict changes in the conditions in the reservoir and to account for $\mathrm{CO}_{2}$ volumes.

- Sampling fluids in the reservoir - During the planned Phase 2, prereflood fluids would be obtained and analyzed. The samples can then be compared with samples taken at later times in the evolution of a flood to depict changes in composition that may aid in better understanding the conditions in the reservoir and the chemistry related to the emulsions.

- Cased hole logging services to identify fluids in reservoir and cap rock - During the planned Phase 2, pulsed neutron, carbon/oxygen type logs (e.g. Baker Atlas' RPM-C GasView) or other types of logs would be run across the EOR target zone and the cap rock layers above to establish baseline conditions for saturation, fluids/gas in pore space, porosity, and lithology. This baseline case would then be used to compared with subsequent runs to demonstrate that the $\mathrm{CO}_{2}$ has been sequestered in the target formation and/or to identify leakage pathways along the wellbore that could then be remediated.

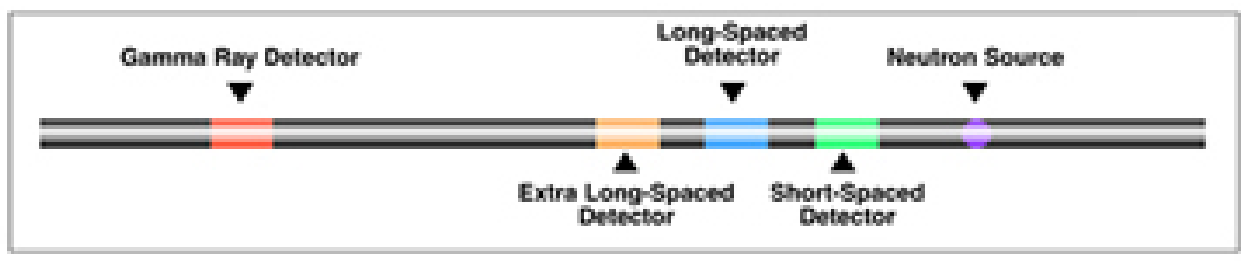

Baker Atlas Gas View Log: The three high-resolution detectors in the RPM-C instrument are arranged to receive both capture and inelastic gamma rays and to sample the neutron-gamma transport over a longer baseline than conventional tools. 
- Latest generation cement bond logs to evaluate cement bonding During the planned Phase 2, a second generation cement bond log (e.g. Baker Atlas' Segmented Bond Tool) could be run to determine the quality of bonding in all wells to be used in EOR operations. If any cement bonding issues were identified that warrant repair, then a remediation plan could be developed and implemented.



- Casing inspection logs to determine condition of casing - During the planned Phase 2, casing inspection logs (e.g. Baker Atlas' MicroVertilog: Magnetic Flux Leakage Inspection) would be run in all wells to be used in EOR operations to determine the physical condition of the long casing strings to be utilized during injection/production. If any casing integrity issues are identified that warrant repair, then a remediation plan would be developed and implemented.

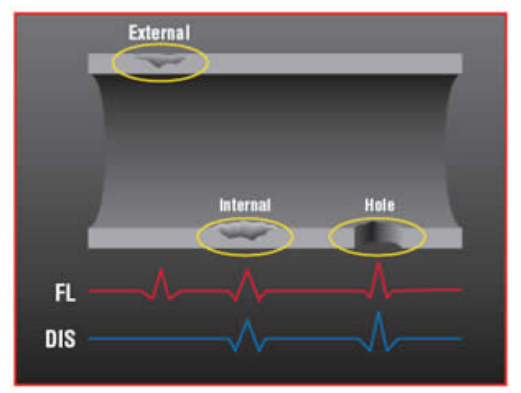

Baker Atlas MicroVertilog: Typical flux leakage (FL) and discriminator (DIS) sensor response to common defects - The FL sensors respond to internal and external anomalies, while the DIS sensors respond to internal anomalies only.

- Mechanical integrity testing (MIT) of wellbores to be utilized in demonstration - During the planned Phase 2, any wells that would be utilized for injection of $\mathrm{CO}_{2}$ would have a Mechanical Integrity Test (MIT) performed in accordance with EPA UIC requirements.

- Plan designed to correct deficiencies discovered by the work/tests performed - During the planned Phase 2, any wellbore deficiencies that might have been discovered as a result of reviews, data collection, logging 
operations, etc., would have a remediation plan developed and implemented to correct identified deficiencies.

- Identifying surface and downhole equipment that would be used during a planned operating phase (e.g. injection, production, taking of measurements, monitoring for leakage) - During Phase 1, surface and downhole equipment for a typical three well EOR field were identified. The equipment was selected based on Core Energy's experience with seven other fields in the area and to meet EPA Class II UIC Rules and the requirements of other agencies with jurisdictional oversight (e.g. Michigan DNRE). The Phase 2 plan was that the equipment would be purchased and installed.

- Plan to flood the reservoir with $\mathrm{CO}_{2}$ (sequestering it) that utilized existing wellbores when and incorporating new wellbores as deemed necessary (i.e. reservoir model/simulation) - During the planned Phase 2 , utilizing the existing 3-D seismic survey, field review, wellbore inventory, review of logs and cross-sections, reservoir voidage, logging operations, etc., a reservoir model would be developed for use in the project.

Figure 9 is a Gantt chart showing the approximate timelines planned for each of the activities identified and described herein as a part of the EOR MVA Plan.

\subsubsection{Operating Phase Plan (Injection of $\mathrm{CO}_{2}$ into sinks):}

Technologies/Activities originally planned for the operating phase of the demonstration included:

- Wellbores would be constructed and operated to meet all EPA requirements (e.g. MIT, Class II EPA UIC Permits).

- Data would be reported to EPA and other regulatory agencies per requirements.

- Accurate measurement of the $\mathrm{CO}_{2}$ injected into the field using mass flow meters - During planned Phase 2 operations, coriolis mass flow meters would be utilized to measure volumes of $\mathrm{CO}_{2}$ injected into the wells/field. Published mass flow accuracy for Micro Motion's F-Series meters is $\pm 0.10 \%$. 


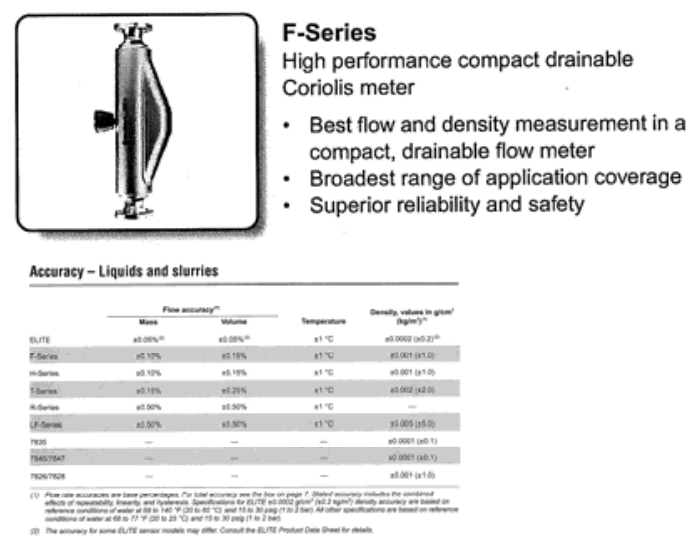

- Accurate measurement of the $\mathrm{CO}_{2}$ and other produced fluids using typical oil field metering systems.

- Accurate continuous measurement of surface (e.g. injection and annulus) and periodic downhole pressures during injection and production - During the planned Phase 2 injection and for a period following, surface injection pressure and temperature would be measured and recorded continuously to develop a history. The data would be used in determining reservoir injectivity, ensuring conditions of EPA UIC Permit are adhered to, and diagnosing operational matters.

The annular pressures between the injection/production tubing and longstring casing and the long-string casing and intermediate casing would be monitored daily as a diagnostic step to further aid in detecting wellbore integrity issues.

At pre-determined injection volumes (e.g. 1/3 and 2/3 of estimated fill-up volume), injection would be temporarily shut-down to allow for bottom hole pressure data to be collected and analyzed for use in both reservoir understanding and to aid in leak detection.

- Periodic sampling of produced fluids (gases) to compare with baseline samples - During planned Phase 2 injection, fluid/gas samples would be taken at least two times (e.g. corresponding with downhole pressure surveys and at the conclusion of fill-up) to identify and track composition and discern changes and/or trends.

- Periodic running of cased hole logging services to compare with baseline run - During planned Phase 2 injection, at the midway point and then again at the end of the demonstration injection period; again run pulsed neutron and carbon/oxygen type logs (e.g. Baker Atlas' RPM-C GasView) across the EOR target zone and the cap rock layers above to compare with the baseline log run pre-injection.

If any leakage of $\mathrm{CO}_{2}$ were to be identified, a plan to remediate the leakage pathway would be developed and implemented. 
- $\mathrm{CO}_{2}$ monitoring equipment would be placed at the injection wellheads to detect surface leaks related to injection operations - During planned Phase 2 injection, $\mathrm{CO}_{2}$ detectors would be placed at the wellheads of injection wells, due to their elevated risk of leakage during the injection phase.

The detectors would continuously monitor the atmospheric $\mathrm{CO}_{2}$ concentrations. If any rapid or significant increase over the normal or background atmospheric $\mathrm{CO}_{2}$ concentration is detected, an alarm would be triggered which dispatches a field operator to the site and/or automatically shuts the injection system in, thus, stopping the flow of $\mathrm{CO}_{2}$.

4.1.3 Closure Phase (Injection ceased, wells plugged and abandoned, equipment and facilities removed, sites restored):

It should be noted that EOR operations would have most likely continue on for a considerable amount of time beyond the WCCS P Phase 2 demonstration, therefore, these things would not likely occur during the life of the planned project. They are being shown only to illustrate the types of activities that would typically be performed during the closure phase of an MVA Plan.

Technologies/Activities during the closure phase of the demonstration would include:

- Final volume of $\mathrm{CO}_{2}$ sequestered would be documented, reported and kept on file.

- Final measurement of reservoir pressures to compare with material balance for volume of $\mathrm{CO}_{2}$ injected and volumes of oil, gas and water produced.

- Final sampling of all produced fluids (gases) to compare with baseline and operating samples.

- Running of final cased hole logging services to compare with baseline and operating phase runs.

- Running of final casing inspection logs to compare with baseline run.

- Wells would be plugged in accordance with the requirements of all regulatory agencies that have jurisdictional oversight (e.g. EPA, DNRE).

- Equipment and facilities would be removed from wells and locations restored.

4.1.4 Post-Closure Phase (ongoing monitoring to demonstrate that sequestration had occurred and that it was safe to discontinue further monitoring):

Again, it is noted that EOR operations would most likely continue on for a considerable amount of time beyond the WCCSP Phase 2 demonstration, therefore, these things would not likely occur during the life of the project. They are being shown only to illustrate the types of activities that would typically be performed during the post-closure phase of an MVA Plan. 


\section{Technologies/Activities during the post-closure phase of the demonstration would include:}

- Periodic visual checking of well sites to look for leaks and impact on vegetation.

- Other post-closure monitoring requirements that may be prescribed by regulatory agencies who have oversight. These types of regulations are a work in progress.

\section{Assessment of Emulsion-EOR Oil Production}

The Dover 33 field in the Niagaran reef produced 1.3 Mbbl of crude oil in primary production from 1974 through 1996. In 1998, the production of $\mathrm{CO}_{2}$-EOR commenced, which produced an additional 500,000 bbl oil through 2007. However, production declined to about $3 \mathrm{bbl} / \mathrm{d}$. In laboratory experiments, using a surrogate emulsion consisting of water-in-dodecane emulsion stabilized by carbon black particles, we found that such emulsions are about $50 \%$ more effective in recovering crude oil from a sand column than dodecane alone. (Dodecane was used as a surrogate for $\mathrm{CO}_{2}$, because it allowed work at atmospheric pressure.) Therefore, we expect that the injection of a water-in-carbon dioxide emulsion would be about 50\% more effective in extracting crude oil from the Dover 33 field compared to neat $\mathrm{CO}_{2}$-EOR, that is we would extract about $4.5 \mathrm{bbl} / \mathrm{d}$ of oil. Much larger yields cannot be expected, because by now most of the relatively low viscosity and $\mathrm{CO}_{2}$-soluble hydrocarbons have been extracted from that field. Nevertheless, these tests may demonstrate to the oil industry at large the advantage of using an emulsion-EOR compared to neat $\mathrm{CO}_{2}$-EOR.

\section{Obtain Federal and State Permits for Emulsion Injection}

All necessary permits were already in place for the intended beneficial use of conducting $\mathrm{CO}_{2}$ enhanced oil recovery operations. The State of Michigan Department of Environmental Quality provided preliminary approval for modifications to existing permits that would have allowed $\mathrm{CO}_{2}$ to be augmented with particles for PSEs at the 1 to $2 \%$ level. An Environmental Information Volume (EIV) is was prepared for submission with the Phase 2 proposal.

\section{Particle Stabilized EmulsionsBackground}

In general, two types of particle stabilized emulsions (PSE) can be formed: (a) Water-inCarbon Dioxide (W/C), and (b) Carbon Dioxide-in-Water (C/W). W/C emulsions are obtained with hydrophobic particles; $\mathrm{C} / \mathrm{W}$ emulsions are obtained with hydrophilic particles (Golomb et al., 2006). In W/C emulsions, tiny droplets of water are dispersed in liquid (or supercritical) $\mathrm{CO}_{2}$; in $\mathrm{C} / \mathrm{W}$ emulsions, tiny droplets of liquid (or supercritical) $\mathrm{CO}_{2}$ are dispersed in water. The ultrafine particles form a sheath around the dispersed droplets, preventing their coalescence into a bulk phase. Without a sheath of particles, the dispersed droplets (either carbon dioxide or water) would coalesce within seconds to form two separate phases with a sharp meniscus between them. The particles present a kind of electrostatic barrier to the droplets, preventing them from bumping into each other, and hence forming larger droplets, and eventually a bulk phase (Aveyard et al., 2003). In our previous experiments, we found that PSE are quite stable for prolonged 
periods. Surrogate PSE, using organic liquids (e.g. octoil or dodecane) were kept on laboratory shelves in glass vials for years without disintegration. They even survived travel on airplanes or automobiles for demonstration purposes at scientific conferences. $\mathrm{W} / \mathrm{C}$ or $\mathrm{C} / \mathrm{W}$ emulsions have to be kept under pressure to prevent flashing of liquid $\mathrm{CO}_{2}$ into vapor. We kept $\mathrm{W} / \mathrm{C}$ or $\mathrm{C} / \mathrm{W}$ emulsion in a pressure view cell for up to 48 hours, without notable disintegration.

\section{Emulsion Formation Apparatus}

A modified Particle Stabilized Emulsion (PSE) formation apparatus was constructed, functionally tested, and emulsion formation demonstrated. The system is depicted in Figure 10. The heart of the system is a Kenics type static mixer. This is a stainless steel tube of preselected diameter with curved elements (see Figure 2). Using high flow rates and high pressure (high Reynolds numbers), the flow in the static mixer is highly turbulent. Under those conditions, the ingredients flowing into the static mixer are thoroughly dispersed. The higher the shear force, i.e. flow rate, the better the mixing and the dispersion of one fluid into another. We selected the static mixer as the dispersing device because it produces a continuous flow, rather than a batch reactor with mechanical mixing, which would have to be reloaded with fresh ingredients after discharge. Furthermore, the static mixer is commercially available and capable of $\mathrm{mL} / \mathrm{min}$ to $\mathrm{gal} / \mathrm{min}$ flow rates.

Two types of static mixers were used in our tests. One was $1 / 4$ inch OD, 11 inch long, 40 baffles. The other was 3/16 inch OD, 11 inch long, 60 baffles.

The static mixer is fed with three types of fluids: (1) liquid or supercritical carbon dioxide; (2) water; and (3) a slurry of ultrafine particles in water or ethanol. The proportion of water/carbon dioxide is varied according to needs. For enhanced oil recovery, the proposed proportion is $70 \%$ by volume $\mathrm{CO}_{2}, 30 \%$ by volume $\mathrm{H}_{2} \mathrm{O}$. For permanent sequestration of $\mathrm{CO}_{2}$, the proposed proportions are inverted, a higher percentage of $\mathrm{H}_{2} \mathrm{O}$, and a smaller percentage of $\mathrm{CO}_{2}$. Heating elements around the inlet and around the static mixer allows formation of an emulsion with liquid or supercritical $\mathrm{CO}_{2}$, respectively. The critical constants of $\mathrm{CO}_{2}$ are $\mathrm{T}_{\mathrm{c}}=31^{\circ} \mathrm{C}\left(88^{\circ} \mathrm{F}\right), \mathrm{p}_{\mathrm{c}}=7.3 \mathrm{MPa}(1073$ psi). Because it is difficult to obtain a homogeneous slurry of particles in water (particles tend to agglomerate, i.e. form clumps), a separate concentrated slurry of particles is obtained in a stirred container, sometimes with the aid of a surfactant, or in a different medium than water, e.g. ethanol. The three fluids are fed into three separate syringe-type pumps (Teledyne ISCO A1000 continuous flow syringe pump for $\mathrm{CO}_{2}$, and $500 \mathrm{D}$ for water and slurry). The three syringe pumps deliver their content at equal pressure, 2000 psi, to the static mixer at a preselected flow rate, in order to obtain the desired proportions of $\mathrm{CO}_{2}$ and $\mathrm{H}_{2} \mathrm{O}$ in the ensuing emulsion. Normally, but not always, the amount of particles is selected to obtain $2 \%$ by weight of particles in the final emulsion.

The formed emulsion flows through a heated tube to raise the temperature of the system to supercritical conditions, and then into a pressure view cell (Figure 11). The view cell is equipped with two 1 inch thick tempered glass windows, 1.75 inch diameter, on each side. One window allows illumination, the other photography or microscopy of the emulsion that flows through the view cell. From the view cell, across a back-pressure regulator, the emulsion flows into a fume hood. There the $\mathrm{CO}_{2}$ flashes into vapor, and is 
exhausted into the atmosphere. The remaining water slurry is dumped into a sink. The emulsion contains no toxic materials.

\section{Results of PSE Formation}

A particle stabilized emulsion was prepared that we proposed to use in Otsego County, MI, for Enhanced Oil Recovery consists of $70 \%$ by volume $\mathrm{CO}_{2}, 30 \%$ by volume of a slurry of carbon black particles in water. The amount of carbon black particles comprises $2 \%$ by weight of the emulsion. The slurry was made up by diluting a commercial product with pure water (AJX3, Solution Dispersions, Inc.) containing $50 \%$ by weight carbon black particles, mean size $200-300 \mathrm{~nm}$. The commercial slurry contains an unknown "anionic" stabilizer in order to prevent carbon black particles from clustering. Because carbon black particles are hydrophobic, the resulting emulsion consists of tiny water droplets sheathed with carbon black particles dispersed in water - a W/C-type emulsion. This type of emulsion was used in the following experiments.

The inlet pressure to the static mixer was 2000 psi and the temperature was $35^{\circ} \mathrm{C}$, therefore, $\mathrm{CO}_{2}$ is in the supercritical state. The view in the pressure cell was completely black, so we could not easily determine globule size. By diverting a small portion of the emulsion through a by-pass line, individual globules could be photographed. Images were taken by a Canon Rebel T2i with varying lenses and attachments. Sizing was performed utilizing a pixel interpolation method and comparison to a known scale. Figure 12 shows individual water droplets sheathed with carbon black particles dispersed in supercritical carbon dioxide. The globule diameters are in the $20-30 \mu \mathrm{m}$ range. Figure 13 shows the mean globule diameter vs. carbon black concentration (\% by weight) in the emulsion. It is seen (a) that the globule diameter is relatively insensitive to the diameter of the static mixer (1/4 or $3 / 16$ inch OD), and (b) that the globules reach a minimum diameter of approximately $20 \mu \mathrm{m}$ at a carbon black concentration greater than about $2 \%$ by weight of the emulsion. We interpret this on account of the packing density of carbon black particles on the surface of the water droplets. In the static mixer, first tiny droplets of water are dispersed in $\mathrm{CO}_{2}$. The droplets are immediately coated with a sheath of carbon black particles, forming the globules. The sheath prevents the globules from coalescence. However, when there is an insufficient number of carbon black particles in the mixer, i.e. weight percent of carbon black in the emulsion, some globules do grow to a larger diameter. This is an important finding. In large scale injection of the emulsion for EOR, the economics are affected, among other things, by the cost of particles. Even if cheap materials are used (e.g. coal), the cost of grinding the coal into nanosize particles increases with the weight percent of particles in the emulsion. Our empirical finding of $2 \%$ by weight of particles in the emulsion is a good guiding principle.

\section{Packing Density}

We model the structure of a globule and the packing density of particles as follows. Figure 14 is a schematic representation of a globule. For a W/C-type emulsion, such as to be used for EOR, the core of the globule is a tiny water droplet. The water droplet is coated with a sheath of hydrophobic particles, represented in the figure as tiny spherical particles on the surface of the spherical water droplet. The sheathed droplet is called a globule. The globule is dispersed in the continuous medium, in our case, liquid or supercritical carbon dioxide. In our experiments, the hydrophobic particles consisted of 
carbon black. For large scale EOR, it may be cheaper to use pulverized coal, grinded to a similar size as carbon black, namely, $200-300 \mathrm{~nm}$.

It is assumed that the particles form a monolayer around the dispersed droplet (Shaw, 1992). We assume that the particles are spherical. If the particles touch each other "head-on," they leave some uncovered interstices, thus occupying $74 \%$ of the droplet surface. A higher packing density of nearly $90 \%$ is achieved if the particles slip one row in regard to the second row. This is similar to packing oranges or apples. Higher packing density can be achieved if every second row of apples in the crate is displaced in regard to the first row.

Taking the water density $\rho_{\mathrm{w}}=1$, carbon black density $\rho_{\mathrm{cb}}=2$, radius of the water droplet $\mathrm{r}_{\mathrm{w}}=100 \mu \mathrm{m}$, radius of the carbon black particle $\mathrm{r}_{\mathrm{cb}}=0.1 \mu \mathrm{m}$, and a packing density of 1 , the mass ratio $\mathrm{m}_{\mathrm{cb}} / \mathrm{m}_{\mathrm{w}}=0.006(0.6 \%)$. If the emulsion consists of $70 \% \mathrm{CO}_{2}$, $30 \% \mathrm{H}_{2} \mathrm{O}$ by volume, the mass ratio $\mathrm{m}_{\mathrm{cb}} / \mathrm{m}_{\mathrm{em}}=0.0018(0.18 \%)$. However, since not all particles are of equal size, and there may be more than a monolayer surrounding the water droplets, it may be safer to use a higher $\mathrm{m}_{\mathrm{cb}} / \mathrm{m}_{\mathrm{em}}$ ratio. In most laboratory tests for $\mathrm{W} / \mathrm{C}$ emulsion formation, we used the formula $70 \%$ by volume liquid or supercritical $\mathrm{CO}_{2}, 30 \%$ by volume $\mathrm{H}_{2} \mathrm{O}, 2 \%$ by weight ( 2 grams per $100 \mathrm{~mL}$ ) carbon black particles. Further experiments are needed to determine an optimal amount of particles in the emulsion.

\section{Preliminary Conclusions}

Based on our laboratory experiments, we found that a Kenics-type static mixer produces excellent particle stabilized emulsions (PSE). Both liquid or supercritical carbon dioxide in water $(\mathrm{C} / \mathrm{W})$, and water in $\mathrm{CO}_{2}(\mathrm{~W} / \mathrm{C})$ emulsions can be created. The former contains $I \mathrm{CO}_{2}$ or $s c \mathrm{CO}_{2}$ droplets dispersed in water; the latter contains water droplets dispersed in $\mathrm{ICO}_{2}$ or $\mathrm{scCO}$. The $\mathrm{C} / \mathrm{W}$-type emulsions are stabilized by hydrophilic particles; the W/Ctype emulsions are stabilized by hydrophobic particles. The emulsion consists of tiny droplets of $\mathrm{CO}_{2}$ or $\mathrm{H}_{2} \mathrm{O}$, respectively, coated with a sheath of particles, hydrophilic or hydrophobic, respectively, dispersed in the continuous phase, $\mathrm{H}_{2} \mathrm{O}$ or $\mathrm{CO}_{2}$, respectively. The sheathed droplets are called globules. The globule size is dependent on the shear force imparted by the static mixer; pressure, number and shape of elements. The globule size is also dependent on surface tension between the liquids, and particle size. For example, supercritical carbon dioxide forms smaller globules compared to liquid carbon dioxide. Smaller particles (nanometer) tend to form smaller globules compared to larger particles (micrometer). The static mixer is available commercially for flow rates of $\mathrm{mL} / \mathrm{min}$ to $\mathrm{gal} / \mathrm{min}$.

During this part of the project, we mainly experimented with a W/C-type emulsion, consisting of $70 \%$ by volume $l$ or $S C \mathrm{CO}_{2}, 30 \%$ by volume of a slurry of commercial carbon black particles (AJX3), $200-300$ nanometer particle size. The amount of particles was usually $2 \%$ by weight of the emulsion, i.e. 2 grams of particles per $100 \mathrm{~mL}$ emulsion. With an 11 inch length, 1/4 inch OD, 40 baffles static mixer, inlet pressure $2000 \mathrm{psi}$, temperature $35^{\circ} \mathrm{C}$ (carbon dioxide in supercritical state), globule diameters were in the $20-30 \mu \mathrm{m}$ range. This type of emulsion would probably perform well in large scale injections into semi-depleted oil reservoirs. In previous unreported laboratory experiments using surrogate apolar organic liquids instead of carbon dioxide, we found that $\mathrm{W} / \mathrm{O}$ (water-in-oil) emulsion are $50 \%$ more effective in extracting 
hydrocarbons from a sand matrix than water or oil alone. We have also set up a high pressure extraction apparatus, where we can extract crude oil from sand matrices using W/C (water-in-carbon dioxide) emulsions.

\section{Emulsion Formation Apparatus}

In this section we concentrated on Water-in-Carbon Dioxide (W/C) emulsions. The W/C emulsion consisted of $70 \%$ by volume supercritical $\mathrm{CO}_{2}$ and $30 \%$ by volume $\mathrm{H}_{2} \mathrm{O}$. One important aspect to consider in the design of the system is the fact that the pore size within the semi-depleted oil reservoir can be on the order of $50 \mu \mathrm{m}$ (Wardlaw et al., 1987). Therefore, it was necessary to design a system, and determine the optimum emulsion formulation, that will produce emulsion globules that are less than the reservoir pore size, to avoid plugging/clogging of the semi-depleted oil reservoir and ensure that emulsion globules will reach the majority of the pore space intact. Carbon Black nanoparticles (AJX3, Solution Dispersions, Inc.) with a mean diameter of $250 \mathrm{~nm}$ were chosen as the hydrophobic particle emulsifier to achieve the required globule size.

The laboratory-scale emulsion system was described previously (Ryan et al., 2011), but is shown here in Figure 10 with additional detail. Two pumps are used to pump water, $\mathrm{CO}_{2}$, and a water/carbon black slurry (Teledyne ISCO A1000 continuous syringe pump for $\mathrm{CO}_{2}$, and a Teledyne ISCO 500D for water and slurry) at 2000 psi. $\mathrm{CO}_{2}$ is pumped at a flow rate of $400 \mathrm{ml} / \mathrm{min}$ and the water/slurry is pumped at $170 \mathrm{ml} / \mathrm{min}$. Heat tape (HTS/Amptek, Duo-Tape, high watt-density) is used for process heating to heat each of the streams to $35^{\circ} \mathrm{C}$ to ensure $\mathrm{CO}_{2}$ is in the supercritical state. The three streams converge and enter the static mixer at a flow rate of $570 \mathrm{ml} / \mathrm{min}$. When the emulsion exits the static mixer it flowed into a fume hood to exhaust the $\mathrm{CO}_{2}$ gas produced. For optical observation, the stream could also be diverted into the high-pressure view cell, for imaging and characterization. The system back-pressure is maintained by utilizing two back-pressure regulators (Tescom 26-1764-24-360). The pressure is reduced across the two back-pressure regulators and process heating is also required to prevent the discharge line from freezing. All tubing, valves and fittings were constructed with 316 stainless steel (SS).

The view cell, constructed of $316 \mathrm{SS}$ and rated to $3000 \mathrm{psi}$, was equipped with two 1 inch thick tempered glass windows, 1.75 inch diameter, on each side. One window allows illumination, the other photography or microscopy of the emulsion that flows through the view cell. When the entire emulsion stream is diverted through the view cell (HV-7 being fully closed, Figure 10) the view is completely black, and imaging/characterization cannot be performed. In order to image and characterize the individual emulsion globules, trials were performed as follows: First, the entire system was purged with supercritical $\mathrm{CO}_{2}$ at $35^{\circ} \mathrm{C}$ and 2000 psi. After the $\mathrm{CO}_{2}$ purging, $\mathrm{CO}_{2}$, water and slurry are pumped, forming the emulsion through the static mixer. Initially, the emulsion was allowed to flow entirely through the main process line ( $\mathrm{HV}-7$ being fully open). The view cell, located on the by-pass line, is essentially a supercritical $\mathrm{CO}_{2}$ reservoir at this point with no emulsion flowing through it. Then, the flow in the main line is throttled down with $\mathrm{HV}-7$, causing a small portion of the flow to be diverted through the by-pass line. Imaging and characterization of the individual emulsion globules is possible in the $\mathrm{CO}_{2}$ diluted chamber. Images were taken using a Canon Rebel 
T2i with varying lenses and attachments. Characterization was performed utilizing a pixel interpolation method with comparison to a known scale located in the view cell. Isolation of the emulsions in the view cell is also possible in order to test for emulsion stability. This is achieved by allowing a portion of the emulsion stream to flow through the view cell. Fully closing valves HV-8 and HV-9 isolates the emulsion within the view cell for observation (Figure 10). Emulsion stability was tested and verified by allowing the W/C PSE to remain under pressure in the view cell for 48 hours. No noticeable changes to the emulsion were observed as the tiny water droplets sheathed with carbon black nanoparticles remained suspended in the bulk phase supercritical $\mathrm{CO}_{2}$.

\section{Results of the Static Mixer Performance}

Trials were performed with the laboratory-scale emulsion system to determine the optimum and most economical emulsion formulation. All trials were conducted with the following parameters: $\mathrm{CO}_{2}$ flow rate of $400 \mathrm{ml} / \mathrm{min}, \mathrm{H}_{2} \mathrm{O}$ /carbon black-slurry flow rate of $170 \mathrm{ml} / \mathrm{min}$, pressure and temperature of $1750 \mathrm{psi}$ and $35 \mathrm{C}$ respectively. Trials were conducted with both a $1 / 4$ inch static mixer, which produced a shear rate of $2760 \mathrm{~s}^{-1}$, and a $3 / 16$ inch OD static mixer which produced a shear rate of $9784 \mathrm{~s}^{-1}$. The average globule diameter vs. carbon black concentration can be seen in Tables 1 and 2 for both the 1/4" and $3 / 16$ " OD static mixers. It was found that a formula consisting of $30 \%$ by volume $\mathrm{H}_{2} \mathrm{O}, 70 \%$ by volume $\mathrm{CO}_{2}$, and $2 \%$ by weight carbon black yielded the smallest mean globule diameter for any given shear rate. Figure 13 displays the results obtained with both the $1 / 4$ " OD and 3/16" OD static mixers, each of which was 11 " in length. Figure 12 is a sample image of the emulsion globules. This particular trial was conducted with a 1/4" static mixer and $2 \%$ carbon black concentration. 
Table 1. Test of $1 / 4$ Inch Static Mixer for Globule Size at Various Carbon Black Levels

\begin{tabular}{|l|l|l|l|l|l|l|}
\hline \multicolumn{7}{|c|}{ wt \% Carbon Black } \\
\hline & $\mathbf{0 . 0 5 \%}$ & $\mathbf{0 . 5 0 \%}$ & $\mathbf{1 \%}$ & $\mathbf{1 . 5 0 \%}$ & $\mathbf{2 \%}$ & $\mathbf{3 . 0 0 \%}$ \\
\hline $\begin{array}{l}\text { Average Globule } \\
\text { Diameter }(\mu \mathrm{m}):\end{array}$ & 73.1 & 30.3 & 23.9 & 21.6 & 17.8 & 18.4 \\
\hline $\begin{array}{l}\text { Standard } \\
\text { Deviation: }\end{array}$ & 36.5 & 11.1 & 10.6 & 13.6 & 6.9 & 9.5 \\
\hline
\end{tabular}

Table 2. Test of $3 / 16$ Inch Static Mixer for Globule Size at Various Carbon Black Levels

\begin{tabular}{|l|l|l|l|l|l|l|}
\hline \multicolumn{7}{|c|}{ wt \% Carbon Black } \\
\hline & & $\mathbf{0 . 5 0 \%}$ & $\mathbf{1 \%}$ & $\mathbf{1 . 5 0 \%}$ & $\mathbf{2 \%}$ & \\
\hline $\begin{array}{l}\text { Average Globule } \\
\text { Diameter }(\mu \mathrm{m}):\end{array}$ & & & & & & \\
\hline $\begin{array}{l}\text { Standard } \\
\text { Deviation: }\end{array}$ & & 31.1 & 32.7 & 21.5 & 17.5 & \\
\hline
\end{tabular}

\section{Design of Scaled-up Emulsion Forming Apparatus for Field Testing}

In preparation for the proposed field testing of a large scale injection of PSE for EOR and PS, we designed an emulsion forming apparatus that would operate at a flow rate of 100 gpm. The prototype system mounted on a skid is shown in Figure 15. Liquid $\mathrm{CO}_{2}$ is supplied by pipeline or truck at a pressure in the 1500 to 3000 psi range. A slurry of particles (hydrophobic for a W/C-type emulsion, hydrophilic for a C/W-type emulsion) is prepared on site or trucked from commercial sources. For on-site preparation of the slurry, bulk materials are shipped in by truck, and appropriate comminution (grinding) equipment is deployed on site. For example, nanometer-size hydrophobic particles may be obtained by further grinding of commercially available pulverized coal; hydrophilic particles by further grinding of commercially available pulverized limestone. The appropriately sized particles are taken up in water to form the slurry. To prevent agglomeration of the particles, sonication of the slurry may be necessary. The aqueous slurry, together with liquid $\mathrm{CO}_{2}$, is introduced into the static mixer to form the emulsion. The formed emulsion is injected underground into a semi-depleted oil reservoir via a pump above the minimum miscibility pressure.

\section{Static Mixer Theory}

A static mixer is an inline, continuous mixing element that contains no moving parts. The emulsion formation system has been designed utilizing a Kenics ${ }^{\circledR} \mathrm{KM}$ static mixer. This unit is constructed of short elements of right and left-handed helices. These elements are alternated and oriented so that each leading edge is at $90^{\circ}$ to the trailing edge of the element ahead. In general, the length of an individual element is approximately 1.5 times the diameter. The element assembly is then enclosed within a pipe or tubular housing. 
Further details were provided in our previously submitted Quarterly Report (Ryan et al., 2011).

The static mixers utilized in this system are constructed from 316 SS. Static mixers are characterized by two unique mixing actions, flow division and radial mixing, which operate simultaneously resulting in the high shear rates required for emulsion formation.

Flow division occurs at the leading edge of each element. The flow divides and follows the semi-circular channel created by the element shape. At each succeeding element the two flows are further divided, resulting in an exponential progression of flow division. This progression is described by the following equation:

$$
\mathbf{S}=\mathbf{2}^{\mathrm{n}}
$$

where $\mathrm{S}$ is the number of striations produced and $\mathrm{n}$ is the number of elements in the static mixer.

Radial mixing, caused by the rotational circulation of the fluid(s) around the hydraulic center of each semi-circular channel, forces the fluid(s) from the diameter of the mixer to the outer wall of the mixer. At the same time, the flow reverses its rotation at each element junction due to the alternating right and left-hand orientation of the elements. It can be observed that a fluid(s) rotation in a given element is opposite the rotational hand of that element. That is, in a right-hand element each semi-circular channel of the fluid contained in that element rotates counter-clockwise. In a left-hand element each semi-circular channel of the fluid contained in that element rotates clockwise. The overall effect of radial mixing is to cause the stream to be continuously and completely inverted radially so that the particles entering at the center of the stream are forced to the outer wall and back again on a continuous basis.

The shear rate in a static mixer, which is a result of the flow profile and the combined effects of flow division and radial mixing, is of primary importance in the design of the emulsion forming system. The shear rate in a static mixer is determined by the following equation:

$$
\gamma=24 \frac{v}{D}
$$

where $\gamma$ is the shear rate in reciprocal seconds $\left(\mathrm{s}^{-1}\right), v$ is the fluid velocity, and $\mathrm{D}$ is the inner diameter of the static mixer. The shear rate is a critical parameter to be used in the scale-up of the laboratory system to the large scale emulsion injection system for field deployment.

Also of importance in the design and subsequent scale-up of the emulsion formation system is the pressure drop in a static mixer. Since a static mixer does not contain any moving parts the only energy required for the mixer is the energy required to overcome the pressure drop. To calculate the pressure drop in an empty pipe for incompressible fluids (in this system the emulsion is treated as an incompressible fluid as the density essentially remains constant throughout the system) the Darcy equation can be used as follows:

$$
\Delta \mathbf{P}=\mathbf{f} \frac{\mathbf{L}}{12 \mathrm{D}} \frac{\rho v^{2}}{2 \mathrm{~g}_{\mathrm{c}}}
$$


where

$\Delta \mathrm{P}=$ pressure drop in empty pipe (psi)

$\rho=$ density of fluid $\left(\mathrm{lb} / \mathrm{ft}^{3}\right)$

$\mathrm{f}=$ friction factor (dimensionless)

$\mathrm{L}=$ length of pipe (ft)

$\mathrm{v}=$ flow velocity $(\mathrm{ft} / \mathrm{s})$

$\mathrm{g}_{\mathrm{c}}=$ gravitational acceleration $\left(\mathrm{lb}_{\mathrm{m}} \bullet \mathrm{ft} / \mathrm{lb}_{\mathrm{f}} \bullet \mathrm{s}^{2}\right)$

$\mathrm{D}=$ inner diameter of pipe (in)

The pressure drop in a Kenics KM static mixer of equivalent length and diameter as an empty pipe is determined by multiplying the calculated pressure drop in the empty pipe by a correction factor, $\mathrm{K}$, such that:

$$
\Delta \boldsymbol{P}_{S M}=\boldsymbol{K} \cdot \Delta \mathbf{P}
$$

where $\Delta \mathrm{P}_{\mathrm{SM}}$ is the pressure drop through the static mixer. The factor $\mathrm{K}$ is a function of the geometry of the mixer elements and the Reynold's Number. Values for the $\mathrm{K}$ factor can be obtained from literature.

It should be noted that, although supercritical $\mathrm{CO}_{2}\left(\mathrm{~T}_{\mathrm{c}}=31^{\circ} \mathrm{C}, \mathrm{P}_{\mathrm{c}}=1073 \mathrm{psi}\right)$ is in fact a compressible fluid, it can be treated as an incompressible fluid in this system. The system pressure remains essentially constant at $2000 \mathrm{psi}$, as there is negligible pressure drop through the system, and the density remains essentially constant.

In general, equations 3 and 4 can be applied to compressible fluids if the $\Delta \mathrm{P}$ is less than $10 \%$ of the inlet pressure.

In order to design a scaled-up emulsion system it is essential to know the shear rates that are required to produce the globules with an average diameter of fewer than 20 $\mu \mathrm{m}$. Table 3 displays the shear rates obtained by each of the static mixers in the laboratory-scale system.

Table 3: Laboratory Trial Shear Rates for the Kenics KM Static Mixer

\begin{tabular}{|c|c|c|}
\hline $\begin{array}{l}\text { Flow: } \\
\text { Total: }\end{array}$ & \multicolumn{2}{|c|}{$\begin{array}{l}400 \mathrm{ml} / \mathrm{min} \mathrm{CO}_{2} \\
170 \mathrm{ml} / \mathrm{min} \mathrm{H}_{2} \mathrm{O} / \mathrm{CB} \text { slurry } \\
570 \mathrm{ml} / \mathrm{min}\end{array}$} \\
\hline Static Mixer OD (in) & $3 / 16^{\prime \prime}$ & $1 / 4^{\prime \prime}$ \\
\hline velocity $(\mathrm{ft} / \mathrm{s})$ & 4.145 & 1.783 \\
\hline ID (in) & 0.122 & 0.186 \\
\hline Shear Rate $\left(\mathrm{s}^{-1}\right)$ & 9784.010 & 2760.944 \\
\hline
\end{tabular}

With knowledge of the required shear rate, one can now size a scaled-up static mixer appropriate for a total flow rate of $100 \mathrm{gpm}$, to be injected into the semi-depleted oil reservoir. However, in order to appropriately design a scaled-up system one would also need to take into consideration the effects of pressure loss and consequently, pumping costs to design the most efficient and economical system. Therefore, a 
spreadsheet calculator was created to calculate the pressure loss in straight piping and the shear rate for static mixers of various sizes, to design the optimum scaled-up system. With knowledge of the pressure loss through straight pipe, the pressure drop through a static mixer of the same diameter is easily calculated using equation 4. A snapshot of this calculator is shown in Figure 16. It is clear that a system designed for an emulsion injection flow rate of $100 \mathrm{gpm}$ should utilize a static mixer with an inner diameter between 1" to 1.5 ".

Another important aspect to consider in minimizing pressure losses is the effect of static mixer length. The longer the static mixer, the greater the pressure loss. There is a trade-off between static mixer length and pumping costs. Within a static mixer there are a given number of elements required to produce globules of a diameter $<20 \mu \mathrm{m}$, any number of elements over this requirement simply provides residence time within the mixer with no appreciable decrease in globule diameter. In an attempt to determine the required number of mixing elements, trials were conducted with two 3/16" OD static mixers of lengths, 11 " and 4.5". These trials were conducted with the same formulation as mentioned previously, with the only variable being the static mixer length (number of mixing elements). These results are shown in Table 4.

Table 4: Results for Varying Static Mixer Length in a 3/16" OD Mixer.

\begin{tabular}{|l|l|l|}
\hline \multicolumn{1}{c}{} & \multicolumn{2}{c|}{ Static Mixer Length } \\
\cline { 2 - 3 } & $\mathbf{1 1}$ in & $\mathbf{4 . 5}$ in \\
\hline $\begin{array}{l}\text { Average Globule } \\
\text { Diameter }(\mu \mathrm{m})\end{array}$ & 17.53 & 17.93 \\
\hline Standard Deviation & 7.84 & 8.75 \\
\hline
\end{tabular}

It is clear that the 4.5 " long static mixer, which contains about 24 mixing elements, produced results very similar to those produced with the 11 " static mixer, which contains about 60 elements. Although more trials are necessary to definitely determine how many mixing elements are required, it can be concluded that elements 25 - 60 are excessive and provide only residence time and greater pressure loss.

\section{Static Mixer Conclusions}

Progress was made in formulating and forming a particle stabilized emulsion (PSE) that would be expected to penetrate a semi-depleted oil formation for EOR and PS. PSEs were formed with globule sizes less than $20 \mu \mathrm{m}$ in diameter. The key is to use a static mixer and shear force in the range of several thousand reciprocal seconds $\left(\mathrm{s}^{-1}\right)$, and stabilizing particles in the tens to a few hundred nanometers in size. A laboratory scale emulsion forming system was designed and tested that achieves the desired emulsion properties. An analysis of the workings of a static mixer was performed that allows selection of the proper parameters for a scaled-up system that could be employed in actual field tests. A preliminary design of such a system was accomplished.

\section{Permanent Sequestration of $\mathrm{CO}_{2}$}

Basically, there are two physicochemical processes for trapping injected $\mathrm{CO}_{2}$ in rock reservoirs: (a) dissolution of $\mathrm{CO}_{2}$ in the aqueous phase (e.g. saline aquifers); (b) mineral 
dissolution and precipitation (Chadwick et al., 2003, Carbon Sequestration Leadership Forum, 2008).

(a) Dissolution. Gaseous, liquid and supercritical $\mathrm{CO}_{2}$ have a limited solubility in water. Even under the high pressures and temperatures prevailing in deep saline aquifers, the solubility of $\mathrm{CO}_{2}$ in brine (which is less than the solubility in pure water) is around 0.5 to $1 \mathrm{~mol} / \mathrm{L}$, about 2.2 to 4.4 weight percent (Rosenbauer and Koksalan, 2002). Thus, limited amounts of injected $\mathrm{CO}_{2}$ can be expected to directly dissolve in the saline aquifer.

Therefore, the risk is high of a greater part of the injected $\mathrm{CO}_{2}$ "bubbling" up to the top of the reservoir from where it may escape through cracks and conduits in the caprock to overlaying potable water reservoirs and possibly back to the surface and the atmosphere. (b) Mineral Dissolution and Precipitation. The governing chemical reaction that leads to mineral dissolution is:

$\mathrm{CaCO}_{3}+\mathrm{CO}_{2}+\mathrm{H}_{2} \mathrm{O} \rightarrow \mathrm{Ca}^{2+}+2 \mathrm{HCO}_{3}^{-}$

It is important to note that only one of the two moles of bicarbonate produced by this reaction is from the injected $\mathrm{CO}_{2}$. The second mole is produced from the dissolution of a mole of carbonate rock. Thus, it is important that the injection of pure $\mathrm{CO}_{2}$ proceed into carbonate rock. When our type of pulverized limestone stabilized emulsion is injected, the $\mathrm{CaCO}_{3}, \mathrm{CO}_{2}$ and $\mathrm{H}_{2} \mathrm{O}$ from the emulsion provides the reactants for reaction (1), thus furthering the dissolution of $\mathrm{CO}_{2}$ into dissolved bicarbonate.

When the emulsion is injected into silicate rock, e.g. anorthite $\left(\mathrm{CaAl}_{2} \mathrm{Si}_{2} \mathrm{O}_{8}\right)$, the following reactions can occur:

first $\mathrm{CO}_{2}$ forms carbonic acid

$\mathrm{CO}_{2}+\mathrm{H}_{2} \mathrm{O} \rightarrow \mathrm{H}_{2} \mathrm{CO}_{3}$

carbonic acid dissociates to provide $\mathrm{H}^{+}$

$\mathrm{H}_{2} \mathrm{CO}_{3} \rightarrow \mathrm{H}^{+}+\mathrm{HCO}_{3}^{-}$

$\mathrm{H}^{+}$reacts with silicate minerals

$2 \mathrm{H}^{+}+\mathrm{CaAl}_{2} \mathrm{Si}_{2} \mathrm{O}_{8}+\mathrm{H}_{2} \mathrm{O} \rightarrow \mathrm{Ca}^{2+}+\mathrm{Al}_{2} \mathrm{Si}_{2} \mathrm{O}_{5}(\mathrm{OH})_{4}$ (kaolinite)

calcite subsequently precipitates

$\mathrm{Ca}^{2+}+\mathrm{HCO}_{3}^{-} \rightarrow \mathrm{CaCO}_{3}+\mathrm{H}^{+}$.

Similar calcite precipitation may occur when the emulsion is injected into carbonate or dolomite rock.

Thus, the injection of our emulsion has a better chance of mineral dissolution and precipitation than the injection of pure $\mathrm{CO}_{2}$, and therefore of permanent sequestration of $\mathrm{CO}_{2}$. 


\section{8. $\mathrm{CO}_{2}-\mathrm{H}_{2} \mathrm{O}$ Emulsion}

As discussed previously, water (polar) and carbon dioxide (non-polar) are very sparingly miscible in each other - solubility about $4.4 \%$ by weight of liquid $\mathrm{CO}_{2}$ in water at 4.5 $\mathrm{MPa}, 15^{\circ} \mathrm{C}$. When mixed together the two liquids form two separate phases with a sharp meniscus between them. However, when the two liquids are mixed in the presence of finely dispersed hydrophylic particles that act as emulsifiers, the mixture forms a stable emulsion with water as the continuous phase and liquid carbon dioxide as the dispersed phase. The solid particles form a sheath around the $\mathrm{CO}_{2}$ droplets and because the particles are hydrophilic they have greater surface area in contact with the continuous aqueous phase (Aveyard et al., 2003). The presence of the particle sheath provides a hindrance to coalescence of the carbon dioxide droplets. Thus, no phase separation occurs.

\section{Experimental \\ 19.1 Materials}

Carbon Dioxide. Industrial grade liquid carbon dioxide was supplied from $50 \mathrm{lb}$ cylinders equipped with siphon tubes (Northeast Airgas).

Water. Water was either de-ionized and filtered in a laboratory system (Millipore Milli$\mathrm{RO})$, municipal tap water, or artificial seawater $(3.5 \%$ by weight reagent grade $\mathrm{NaCl})$. It is important to stress that for large scale injections of the emulsion there is no need to use de-ionized water; municipal-, waste- or sea-water can be used.

Limestone. Mined pulverized limestone $\left(96.5 \% \mathrm{CaCO}_{3}, 2 \% \mathrm{MgCO}_{3}, 1 \%\right.$ silica and silicates, $0.5 \%$ others) supplied by Huber Engineered Materials, Quincy, IL, was used having a bulk specific gravity of 2.7 and a solubility of $0.0035 \mathrm{~g} / 100 \mathrm{~mL} \mathrm{H} \mathrm{H}_{2} \mathrm{O}$ at $100{ }^{\circ} \mathrm{C}$. The pulverized samples can be purchased with different size distributions. In these experiments mostly Hubercarb ${ }^{\mathrm{TM}}$ Q6 pulverized limestone with a nominal median particle size of $6 \mu \mathrm{m}$ was used. A scanning electron microscope (SEM) image of sample Q6 is shown in Figure 17. It can be seen that some particles are crystalline (rhombohedral), others are irregular. For large scale emulsion injection it may be more economical to grind bulk limestone delivered to the sequestration site using commercial ball mills similar to those used to pulverize bulk coal for coal-fired power plants.

\subsection{Mixing Apparatus}

For continuous mixing of the emulsion ingredients we used a Kenics-type static mixer. The laboratory set-up with the static mixer is depicted in Figure 18. The static mixer was a Koflow $1 / 4-27$ with $0.63 \mathrm{~cm}$ internal diameter, $23.5 \mathrm{~cm}$ length and 27 baffles. A $\mathrm{CaCO}_{3} /$ water slurry was prepared in a reservoir. Calcium carbonate particle sedimentation in the slurry was prevented by using constant recirculation with a pump. The slurry was pumped (Wanner Engineering D04-S) at $10 \mathrm{MPa}$ into a mixing tee upstream of the static mixer. Compressed liquid $\mathrm{CO}_{2}$ from a syringe pump (Isco 500D) at $10 \mathrm{MPa}$ was co-injected into the static mixer. The two fluids were thoroughly mixed in the static mixer, and then flow into the view cell (Jerguson T32-11) in a downward flow. A quarter turn ball valve downstream of the cell may be closed to stagnate the emulsion for observation. The outlet of the cell was throttled through a back-pressure regulator (Tescom 54-2162) and the gas vented into a fume hood. A $35 \mathrm{~W}$ halogen lamp with a parabolic reflector was used for illumination through one of the cell windows. A mat 
reflector was used on the opposite window for reflecting the illumination. Photographs were taken through the same cell window where the illuminating lamp was mounted. A fast frame video camera was used (Olympus C-730UZ) either mounted directly on the window of the cell, or looking through a 40x stereomicroscope (Leitz).

\section{Flow Reactor Results}

The Kenics-type static mixer was fed with a slurry of $10 \mathrm{~g} / \mathrm{L} \mathrm{CaCO} \mathrm{Ca}_{3}$ particles in artificial seawater (as a first approximation of a saline aquifer) and liquid $\mathrm{CO}_{2}$. The flow rates were $1.5 \mathrm{~L} / \mathrm{min}$ slurry and $0.15 \mathrm{~L} / \mathrm{min}$ liquid $\mathrm{CO}_{2}$, both at $10 \mathrm{MPa}$. Because of the white background of excess $\mathrm{CaCO}_{3}$ particles and low resolution, no distinct globules were visible in the Jerguson cell. However, no phase separation of liquid $\mathrm{CO}_{2}$ was noticeable, indicating that a stable emulsion was formed. When the emulsion was brought to rest in the Jerguson cell, the globules were clearly visible (Figure 19). The diameter of the globules was in the $70-100 \mu \mathrm{m}$ range.

\section{Economics}

Huber Engineered Materials, Quincy, IL, sells pulverized limestone Q6 for \$38/t FOB. The median size of Q6 is $6 \mu \mathrm{m}$, its composition is $96.5 \% \mathrm{CaCO}_{3}, 2 \% \mathrm{MgCO}_{3}, 1 \%$ silica and silicates, and $0.5 \%$ others. Alternatively, raw limestone in chunks can be purchased from several quarries for $\$ 5-10 / \mathrm{t} \mathrm{FOB}$, and milled to the desired size on-site. In this case the major cost elements are the capital and operating costs of the grinding mills, resulting in a total cost of about $\$ 13$ per ton of pulverized limestone, including the cost of raw material and shipping. Because we need approximately 0.5 ton of pulverized limestone per ton of liquid $\mathrm{CO}_{2}$, the total cost of providing the pulverized limestone on site is about $\$ 6.5$ per ton of liquid $\mathrm{CO}_{2}$, not including the capital and operating cost of the slurry mixer, which may double the cost of preparing the slurry. Currently, the cost estimates of capturing and liquefying $\mathrm{CO}_{2}$ at a coal-fired power plant range from $\$ 35$ to $\$ 45 / \mathrm{t} \mathrm{CO}_{2}$ (IPCC, 2007). Thus, the sequestration of liquid $\mathrm{CO}_{2}$ in the form of an emulsion would add about $14 \%$ to $18 \%$ to the capture cost of $\mathrm{CO}_{2}$, excluding transport costs to the injection site. However, this additional cost may be justified because the emulsion may lead to permanent sequestration of $\mathrm{CO}_{2}$ compared to the injection of pure liquid $\mathrm{CO}_{2}$.

\section{Flow Through Emulsion Production}

The Kenics-type static mixer was fed with various slurry concentrations from 10 to 50 $\mathrm{g} / \mathrm{L}$ of $\mathrm{CaCO}_{3}$ particles in water. The flow rate for slurry was $1.5 \mathrm{~L} / \mathrm{min}$ and for $\mathrm{CO}_{2}$ it was $0.15 \mathrm{~L} / \mathrm{min}$ liquid $\mathrm{CO}_{2}$, both at $10 \mathrm{MPa}$. Because of the white background of excess $\mathrm{CaCO}_{3}$ particles at higher concentrations, and the low resolution, distinct globules were difficult to visualize in the view cell in every case. However, at lower slurry concentrations distinct droplets of liquid $\mathrm{CO}_{2}$ were noticeable. Figure 20 is a digital image of the view through the window of the high pressure cell as approximately $30 \%$ $\mathrm{CO}_{2}$ is mixed with nearly $70 \%$ deionized water through the static mixer with $2 \% \mathrm{CaCO}_{3}$ added as an emulsion stabilizer. Backlighting causes the image background to be exceptionally bright.

Figure 21 shows a stopped-flow view of $\mathrm{CO}_{2}$-in-water droplets at the lowest concentration of $\mathrm{CaCO}_{3}$ slurry. The $\mathrm{CaCO}_{3}$ is difficult to see except as a haze in the 
otherwise clear liquid in the cell. In this view (Figure 21) droplets have settled to the bottom of the view cell.

Figure 22 is a $\mathrm{CO}_{2}$-in-water emulsion at high slurry concentration with other conditions as described above. $\mathrm{CaCO}_{3}$ particles are visible as a thick layer around individual droplets. Black particles in the image resulted from carryover contamination of carbon black not thoroughly cleaned out of the apparatus from a prior run.

At the time of preparing this Quarterly Report, we are still experimenting with creating $\mathrm{CO}_{2}-\mathrm{H}_{2} \mathrm{O}$ emulsions stabilized by pulverized limestone particles. We strive to create stable emulsions with smaller globule size that may readily penetrate relatively tight formations.

\section{Conclusions}

A survey of the relevant literature indicates that injection of an emulsion of liquid carbon dioxide-in-water stabilized by ultrafine pulverized limestone $\left(\mathrm{CaCO}_{3}\right)$ particles has a better chance of permanent sequestration of $\mathrm{CO}_{2}$ than injecting pure liquid $\mathrm{CO}_{2}$. This results from the presence of an aqueous phase as well as $\mathrm{CaCO}_{3}$ in the emulsion. The emulsion will facilitate the primary reaction leading to dissolution of the $\mathrm{CO}_{2}$ in the form of calcium and bicarbonate ions, and subsequent precipitation of carbonate from the surrounding calcium-silicate rock:

We have tested an apparatus that economically produces an emulsion of liquid carbon dioxide-in-water stabilized by ultrafine pulverized limestone particles. The heart of the apparatus is a Kenics-type static mixer that can be scaled up for field use. These devices are routinely used on large scales in the chemical industry for producing oil-inwater and water-in-oil emulsions. In our case the device is modified for using liquid or supercritical $\mathrm{CO}_{2}$.

\section{References}

Aveyard, R., Binks, B. P., Clint, J. H., Emulsions stabilized solely by colloidal particles, Advances in Colloid and Interface Science, 100-102, 503-546, 2003.

Chadwick, R. A., et al. (2003) Geological $\mathrm{CO}_{2}$ storage sites, GHGT-6, 321-326.

Carbon Sequestration Leadership Forum (CSLF) (2008) $\mathrm{CO}_{2}$ storage capacity estimation, CSLF-T-2008-4.

Intergovernmental Panel on Climate Change (IPCC) (2007) Climate Change 2007, Synthesis Report.

Golomb, D. Barry, E., Ryan, D., Swett, P., Duan, H. (2006) Macro-Emulsions of Liquid and Supercritical $\mathrm{CO}_{2}$ Stabilized by Fine Particles, Ind. Eng. Chem. Res., 45, 2728-2733.

Rosenbauer, R. J. and Koksalan, T. (2002) Experimental determination of the solubility of $\mathrm{CO}_{2}$ in electrolytes, Proceedings of the Geological Society of America, Annual Meeting, Denver, CO. 
Ryan, D.K., Golomb, D.S., Miksch, J., Lewczuk, R., Shi, Guang, Manmode, R., Li, L., Mulagapati, S. and Malepati, C. (2011) Carbon Dioxide-Water Emulsions for Enhanced Oil Recovery and Permanent Sequestration of Carbon Dioxide, Quarterly Report submitted to DOE NETL under award DOE DE-FE0002691, August 31, 2010.

Shaw, D., J., Introduction to Colloid and Surface Chemistry, $4^{\text {th }}$ Edition, ButterworthHeinemann, 1992, p.267

Strazisar, B.R., Wells, A.W., Diehl, J.R., Hammack, R.W. and Veloski, G.A. (2009) Near-surface monitoring for the ZERT shallow $\mathrm{CO}_{2}$ injection project. Intl. J. Greenhouse Gas Cntrl., 3, 735-744.

Wardlaw, N.C., Li, Y. and Forbes, D. (1987) Pore-Throat Size Correlation from Capillary Pressure Curves, Transport Porous Med., 2, 597-614.

Wells, A.W., Diehl, J.R., Bromhal, G., Strazisar, B.R., Wilson, T.H. and White, C.M. (2007) The use of tracers to assess leakage from the sequestration of $\mathrm{CO}_{2}$ in a depleted oil reservoir, New Mexico, USA. Appl. Geochem. 22, 996-1016.

\section{List of Figures}

Figure 1. Particle Stabilized Emulsion Formation Apparatus with Static Mixer.

Figure 2. Static Mixer Schematic.

Figure 3. Pressure View Cell.

Figure 4. Dispersion of Water Droplets in Supercritical $\mathrm{CO}_{2}$ Obtained with Static Mixer.

Figure 5. Water-in-Supercritical $\mathrm{CO}_{2}$ Emulsion Stabilized by Teflon Particles. Globule size $200-300 \mu \mathrm{m}$.

Figure 6. Water-in-Dodecane Emulsion Stabilized by Carbon Balck Particles. Globule size $5-10 \mu \mathrm{m}$.

Figure 7. Schematic diagram of emulsion forming system showing both static mixer and sonolator devices.

Figure 8. Diagram of geologic layers typical of Niagaran pinnacle reef systems.

Figure 9. Gantt chart of originally proposed Phase 2 activities.

Figure 10. Modified emulsion formation apparatus with static mixer

Figure 11. Pressure view cell

Figure 12. Water-in-carbon dioxide emulsion stabilized by carbon black particles.

Globule diameter $20-30 \mu \mathrm{m}$.

Figure 13. Globule diameter vs. carbon black concentration in emulsion.

Figure 14. Globule schematic

Figure 15. Detailed Design of Scaled Up Emulsion Forming Apparatus with Static Mixer for Field Deployment and Testing.

Figure 16: Snapshot of Scale-up Design Calculator.

Figure 17. Scanning Electron Micrograph (SEM) of Huber Engineered Materials Hubercarb Q6.

Figure 18. Schematic of emulsion preparation apparatus with static mixer. 
Figure 19. $\mathrm{CO}_{2}-\mathrm{H}_{2} \mathrm{O}$ emulsion stabilized with Hubercarb Q6 calcite particles. Globule diameter in the 70-100 $\mu \mathrm{m}$ range.

Figure 20. View through window of high pressure cell as approximately $30 \% \mathrm{CO}_{2}$ is mixed with nearly $70 \%$ deionized water through a static mixer with $2 \% \mathrm{CaCO}_{3}$ added as an emulsion stabilizer.

Figure 21. Stopped-flow view of $\mathrm{CO}_{2}$-in-water droplets at lowest concentration of $\mathrm{CaCO}_{3}$ slurry. Droplets have settled to the bottom of the view cell.

Figure 22. $\mathrm{CO}_{2}$-in-water emulsion at high slurry concentration with other conditions as described above. $\mathrm{CaCO}_{3}$ particles are visible as a thick layer around individual droplets.

\section{List of Tables}

Table 1. Test of $1 / 4$ Inch Static Mixer for Globule Size at Various Carbon Black Levels Table 2. Test of $3 / 16$ Inch Static Mixer for Globule Size at Various Carbon Black Levels Table 3. Laboratory Trial Shear Rates for the Kenics KM Static Mixer

Table 4: Results for Varying Static Mixer Length in a 3/16" OD Mixer. 


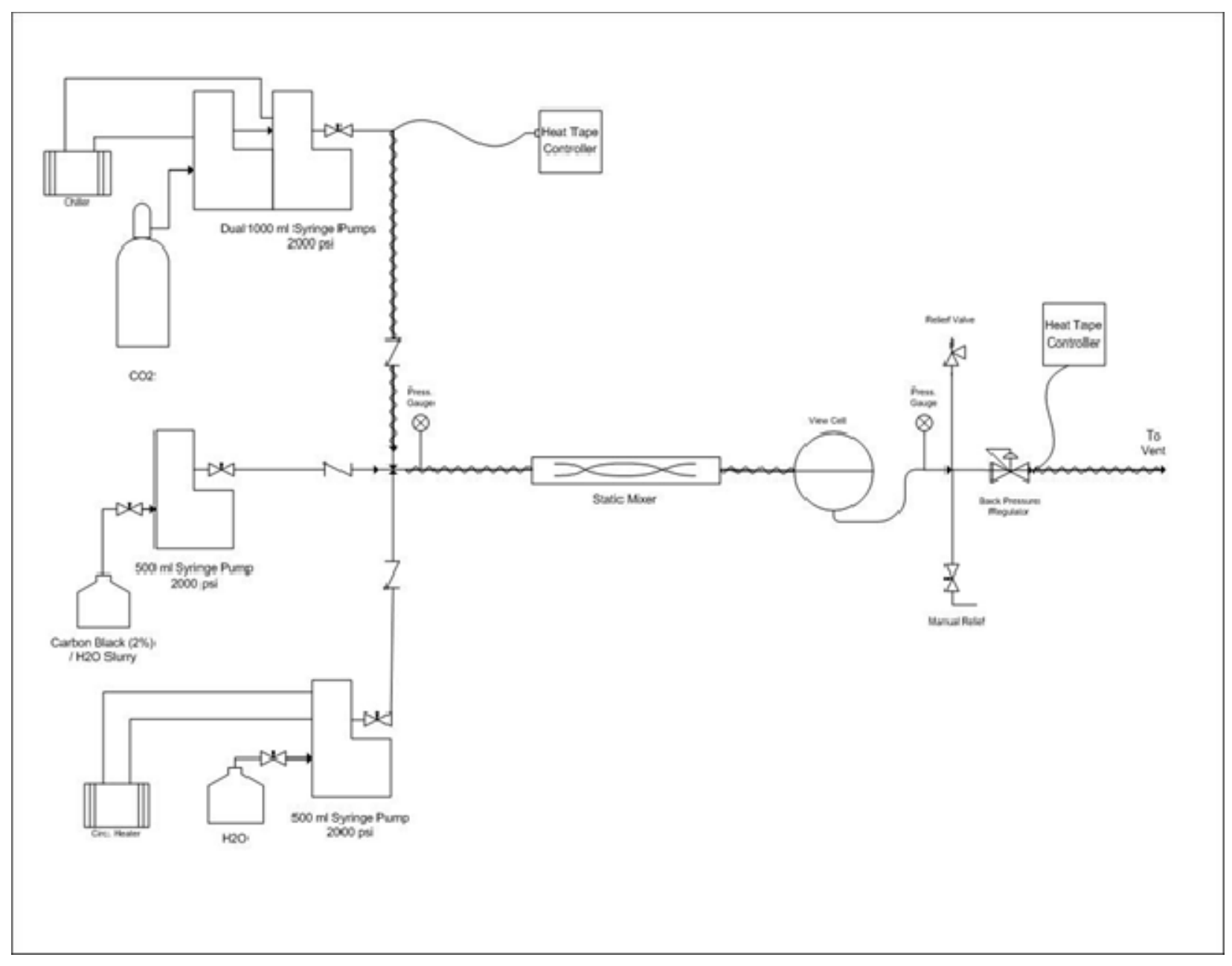

Figure 1. Particle Stabilized Emulsion Formation Apparatus with Static Mixer 


\section{Kenics-type Static Mixer Detail}

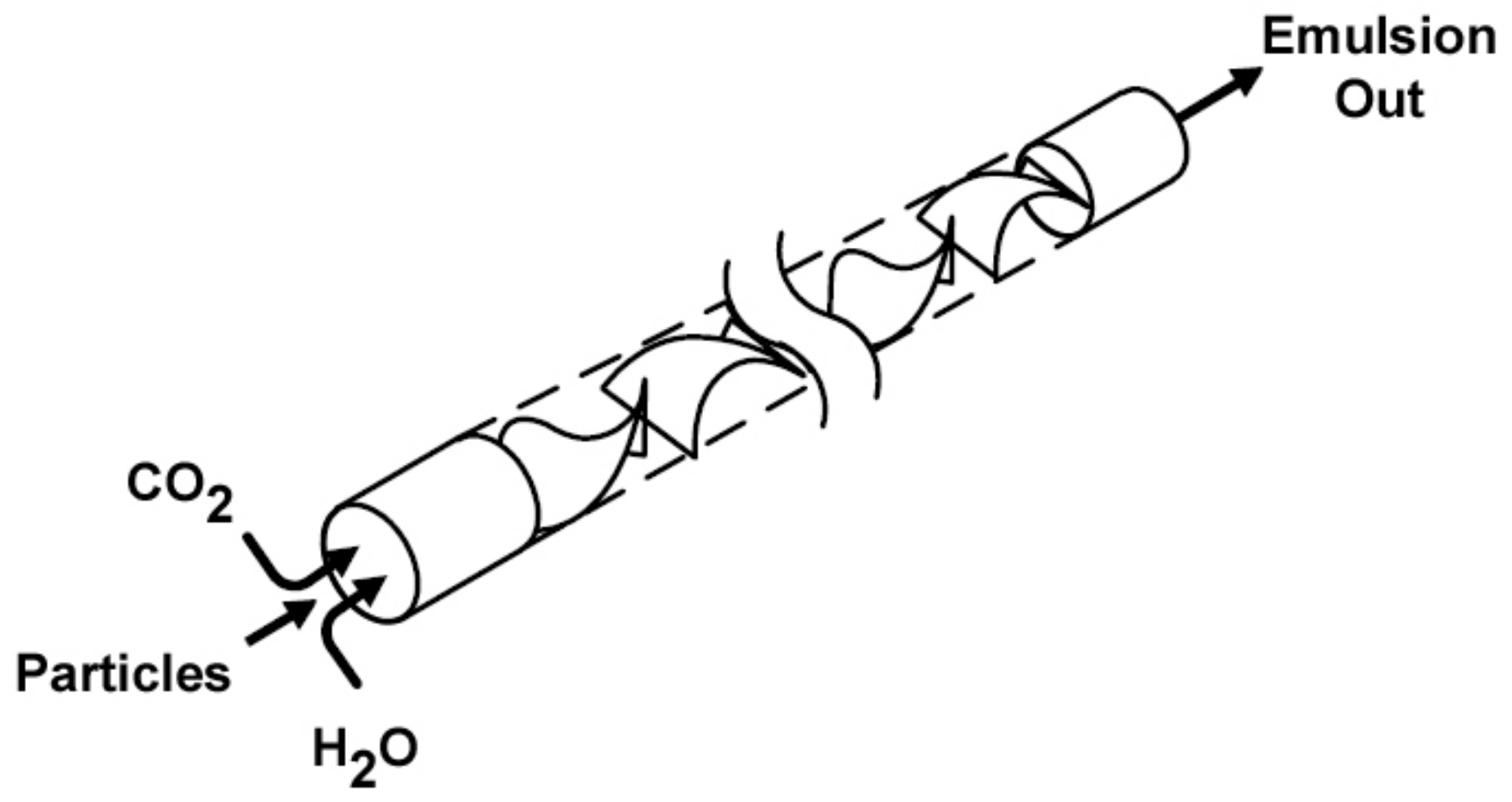

Figure 2. Static Mixer Schematic 


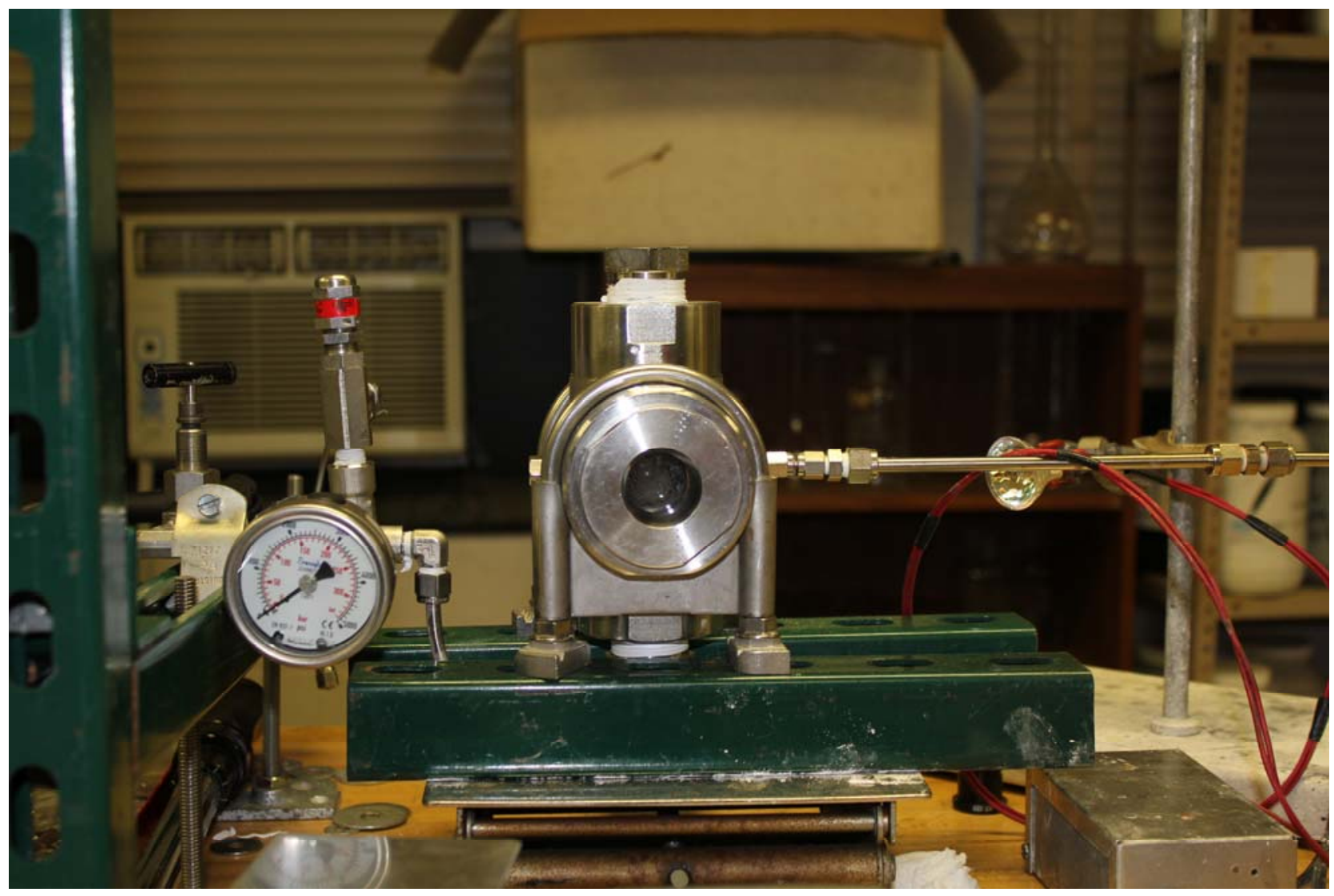

Figure 3. Pressure View Cell 


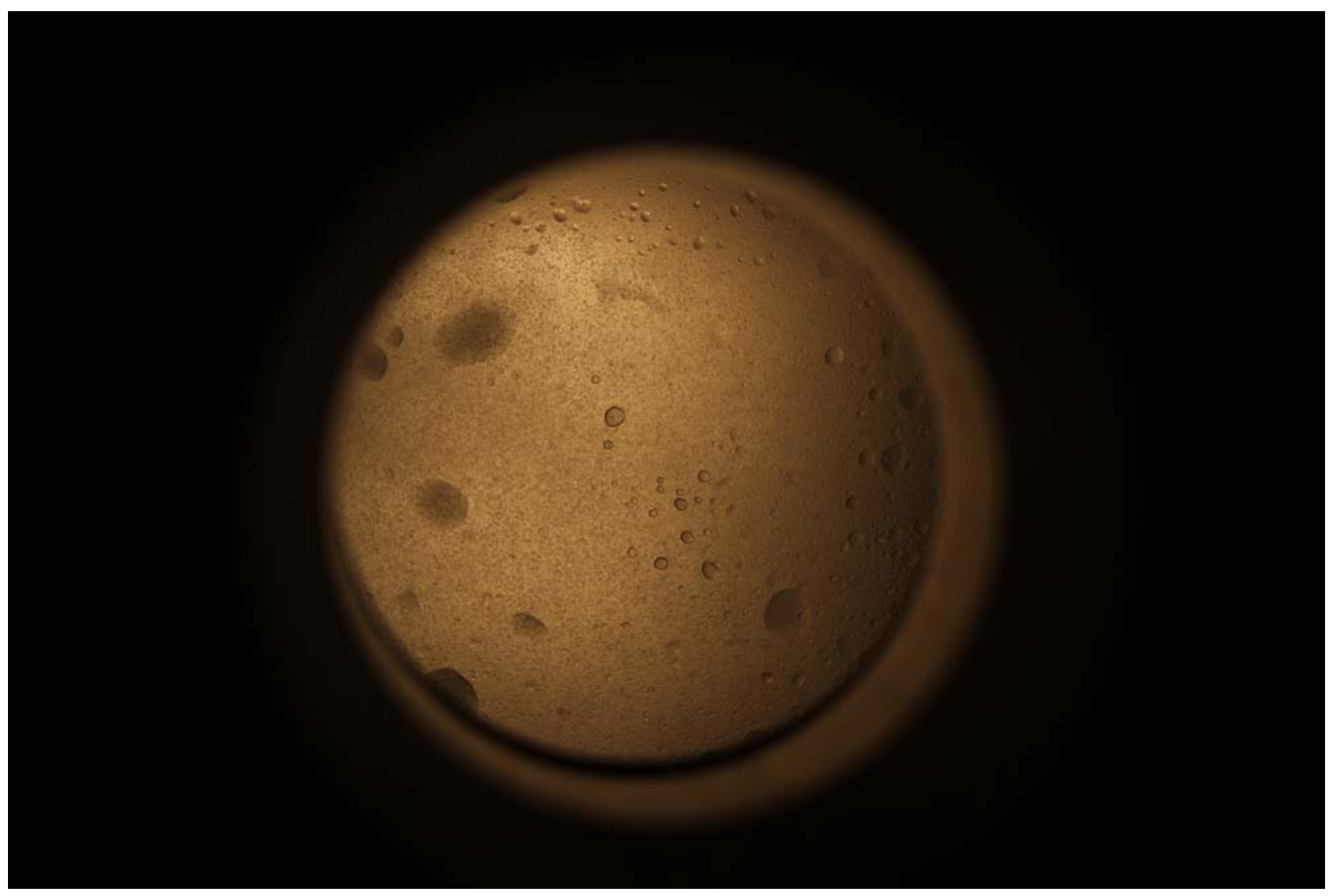

Figure 4. Dispersion of Water Droplets in Supercritical $\mathrm{CO}_{2}$ Obtained with Static Mixer. Water droplets in the $20-30 \mu \mathrm{m}$ range. Large stains are water drops adhering to window. 


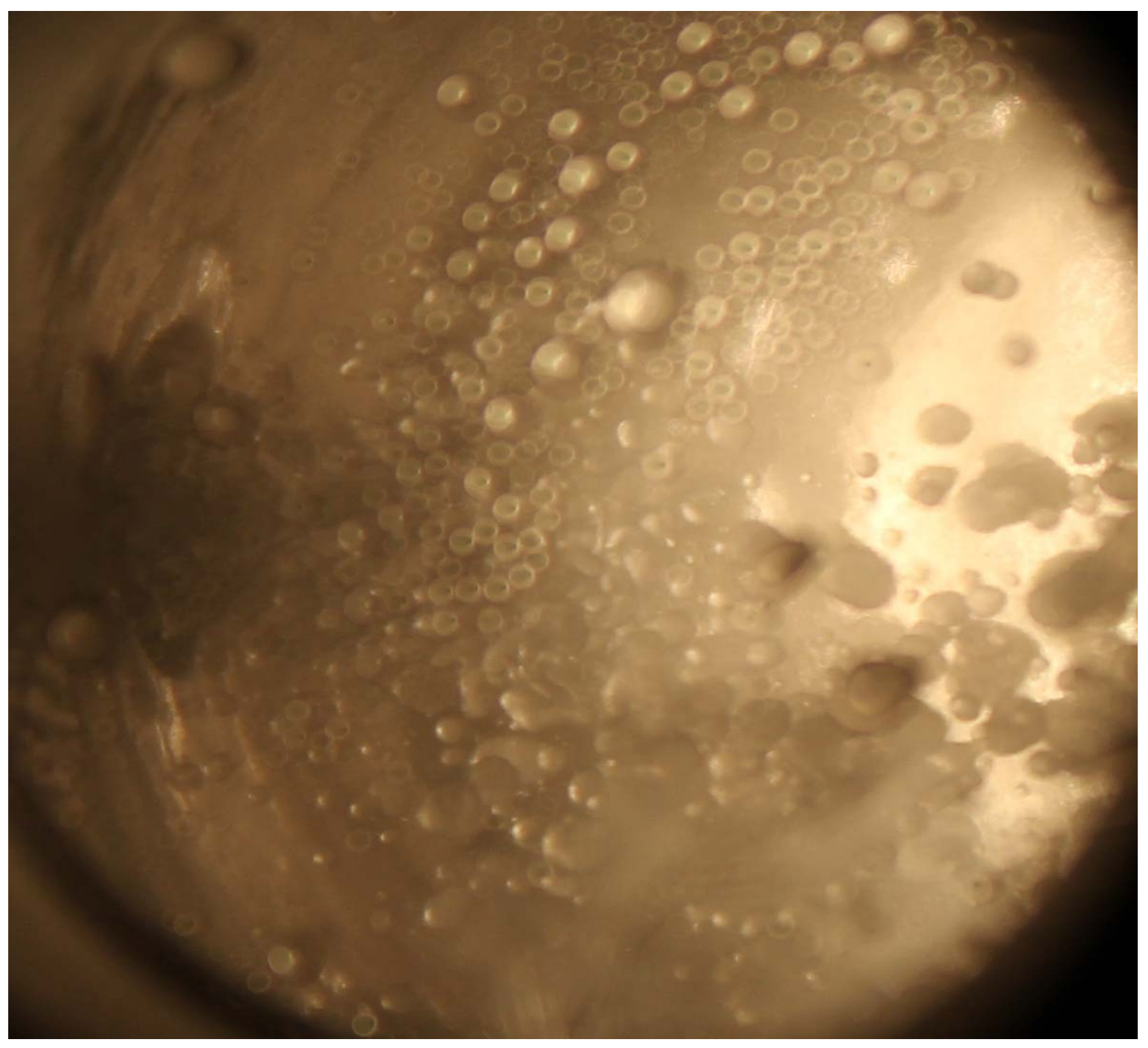

Figure 5. Water-in-Supercritical $\mathrm{CO}_{2}$ Emulsion Stabilized by Teflon Particles. Globule size $200-300 \mu \mathrm{m}$. 


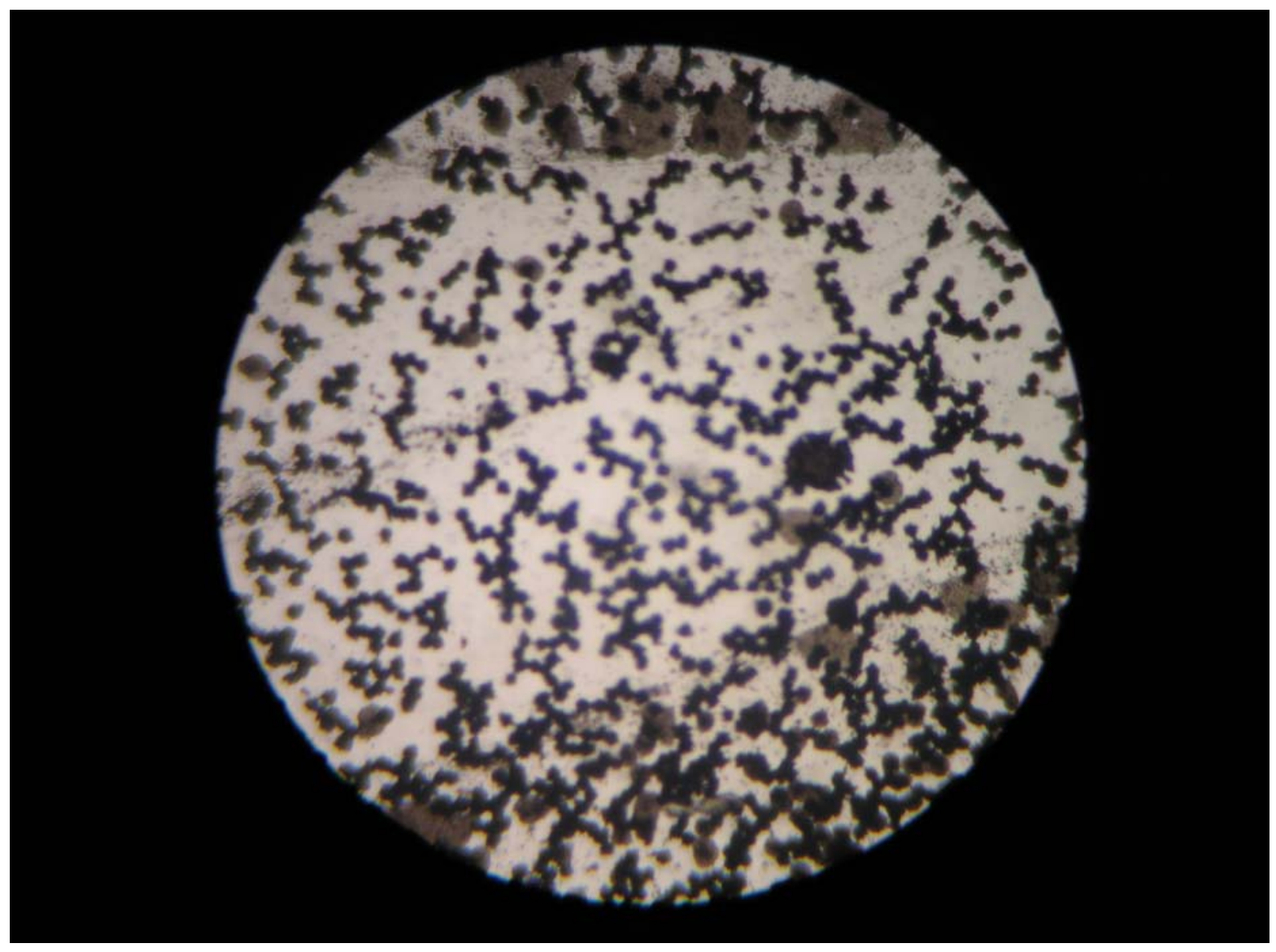

Figure 6. Water-in-Dodecane Emulsion Stabilized by Carbon Balck Particles. Globule size $5-10 \mu \mathrm{m}$. 


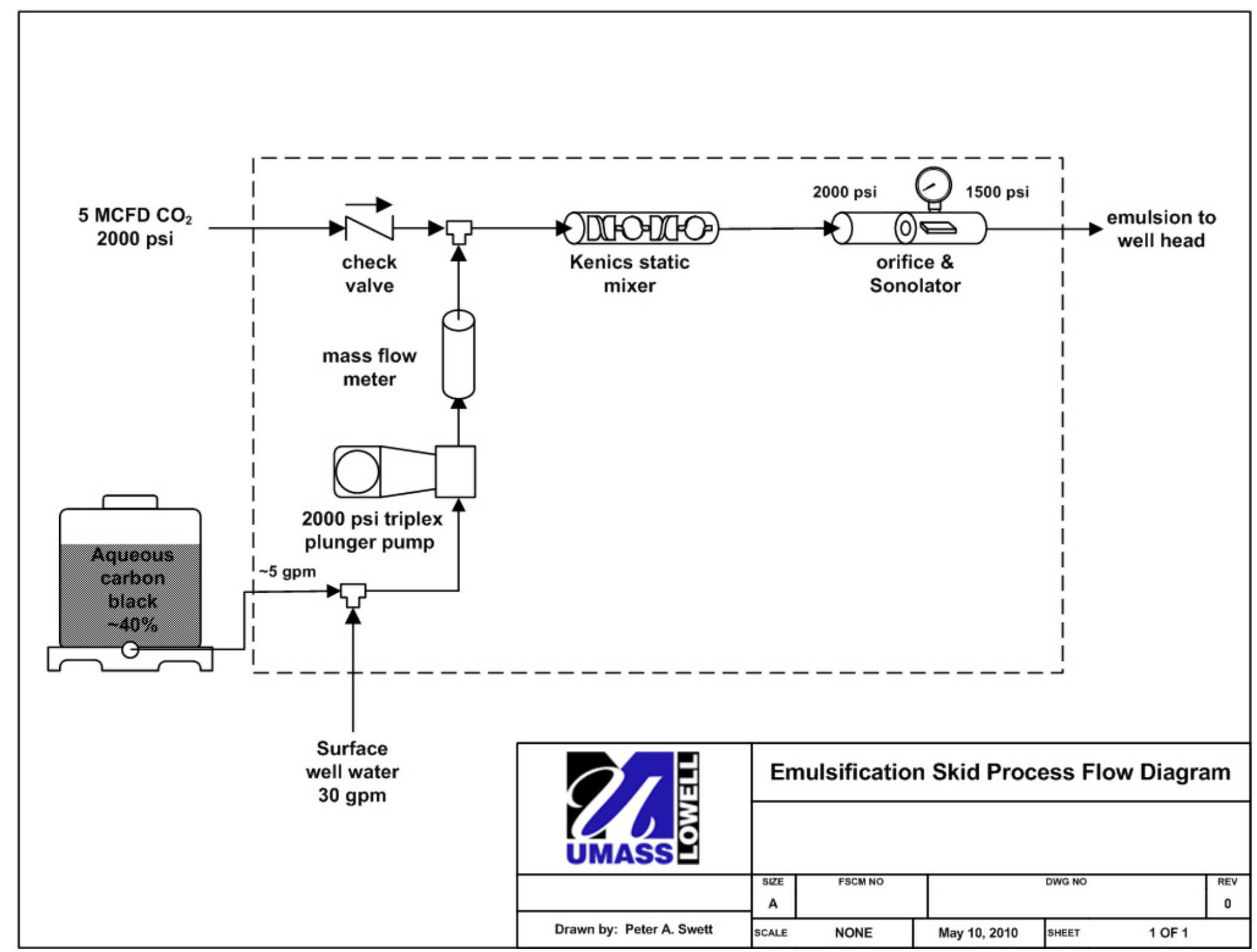

Figure 7. Schematic diagram of emulsion forming system showing both static mixer and sonolator devices. 


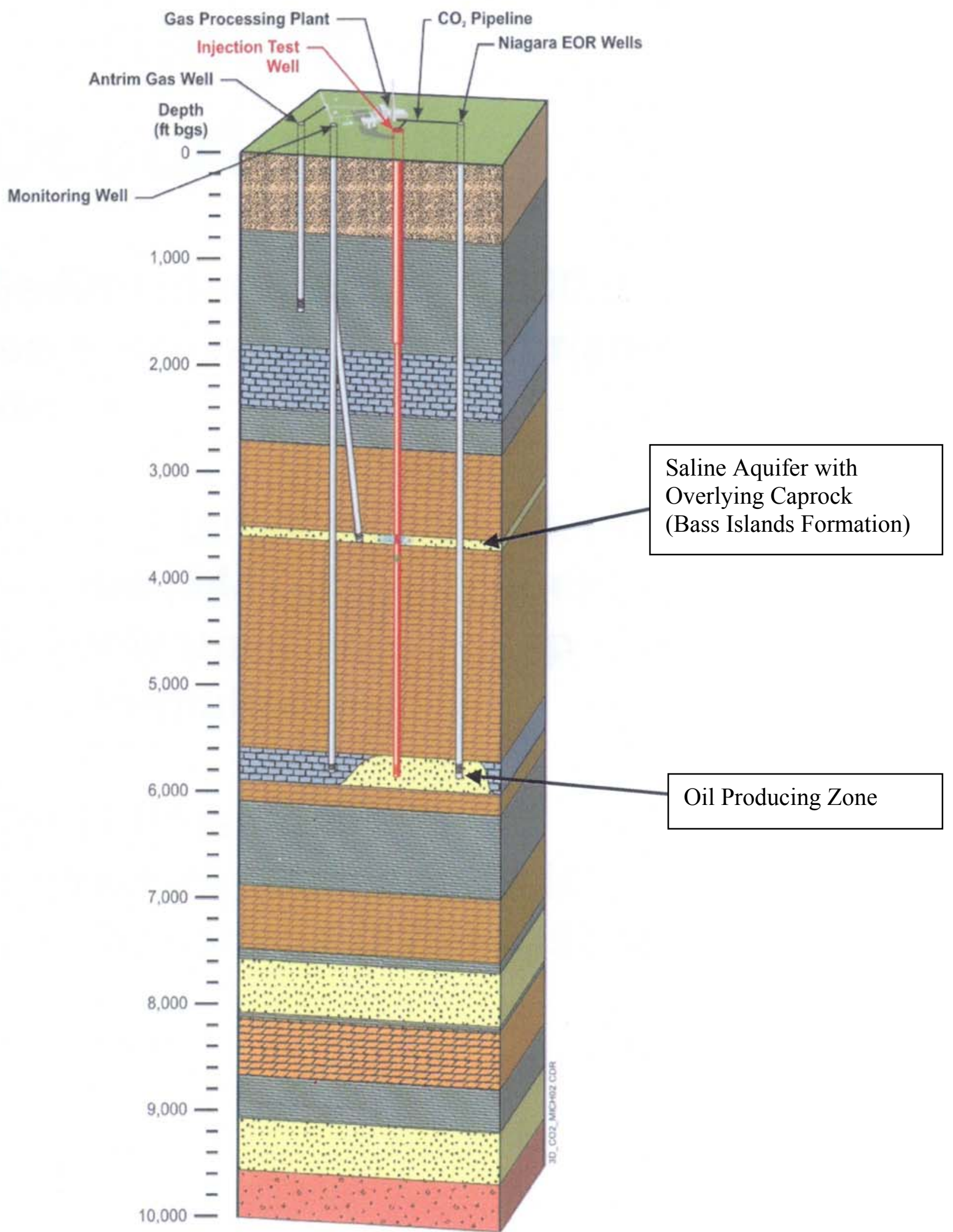

Figure 8. Diagram of geologic layers typical of Niagaran pinnacle reef systems. 


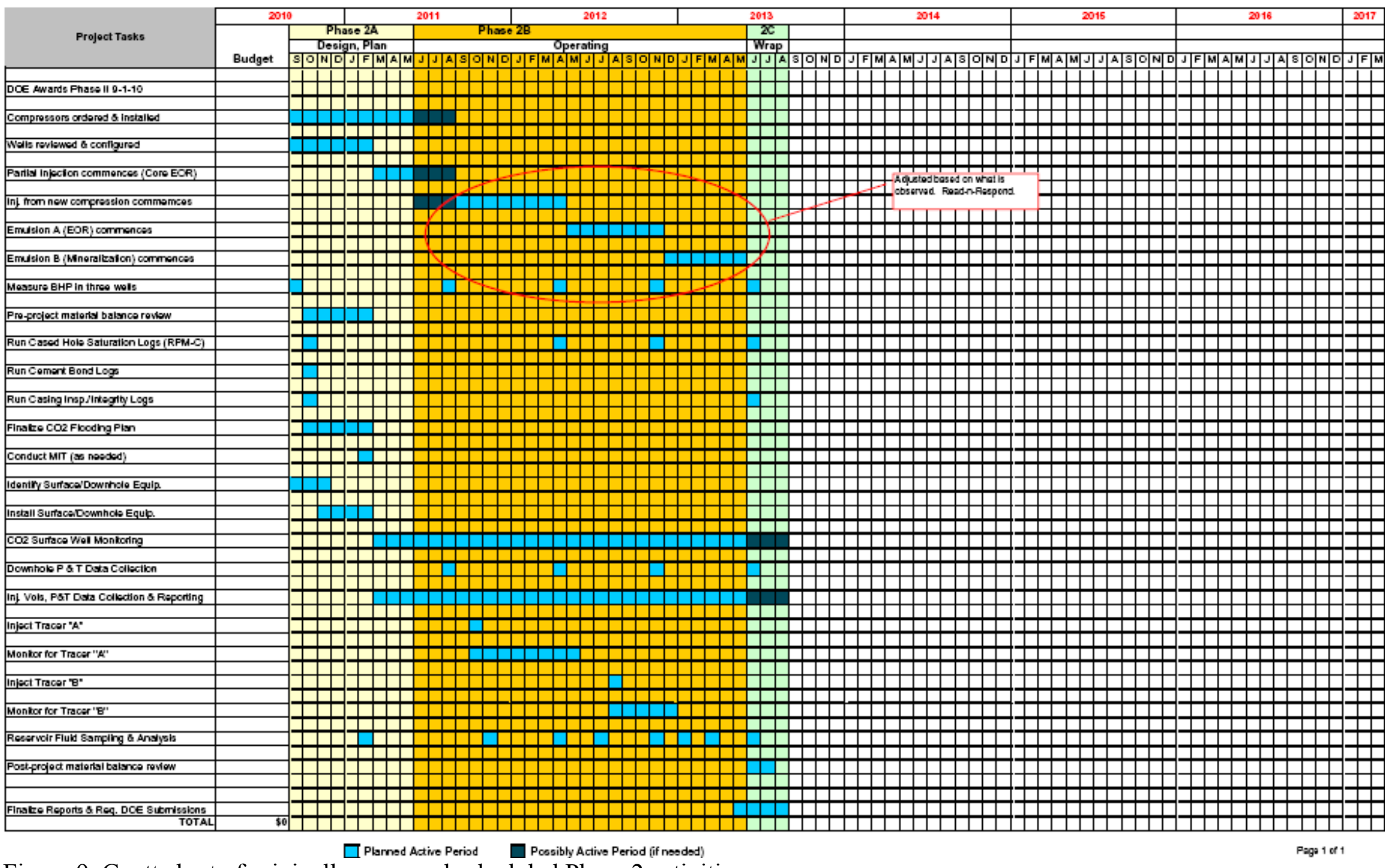

Figure 9. Gantt chart of originally proposed scheduled Phase 2 activities. 


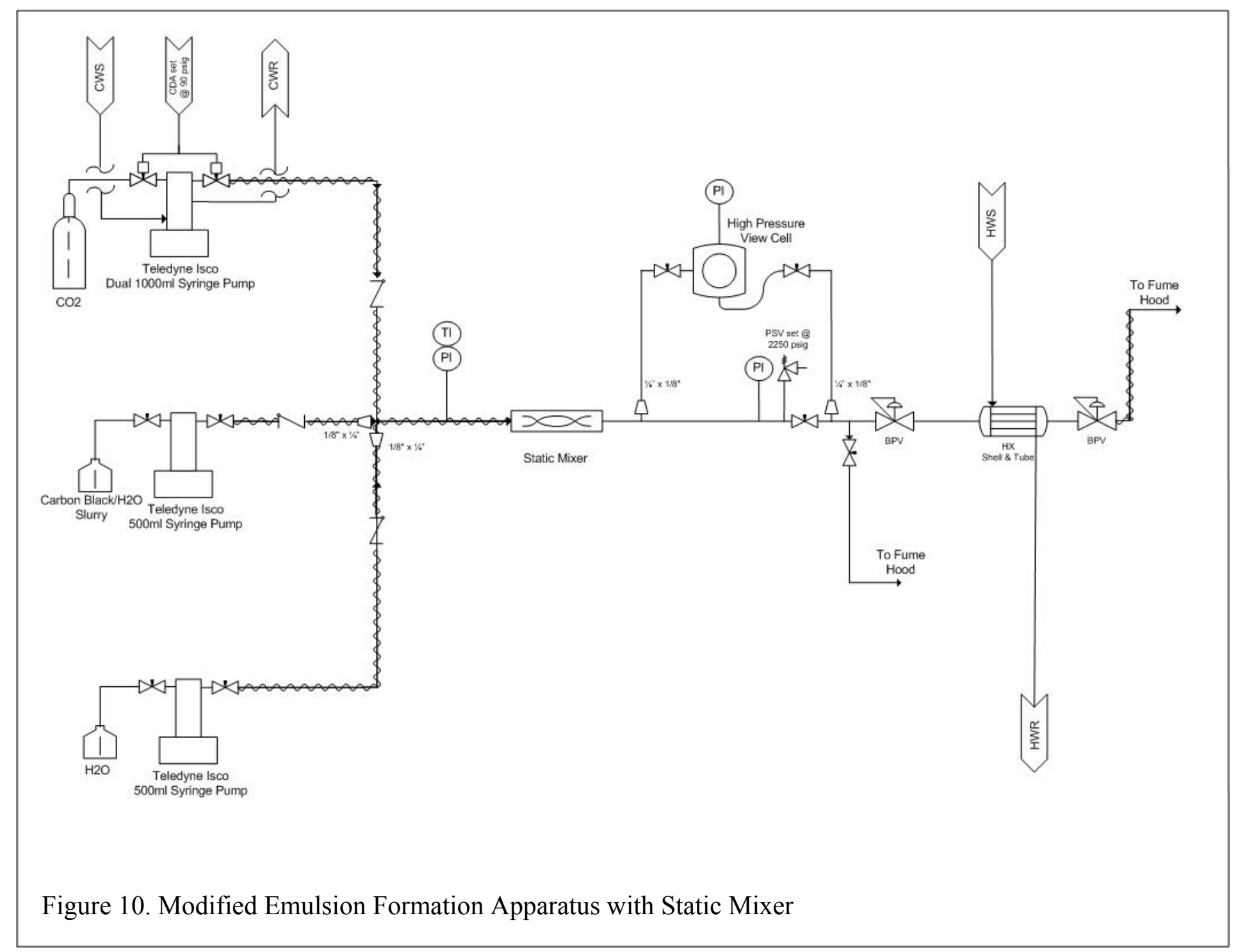




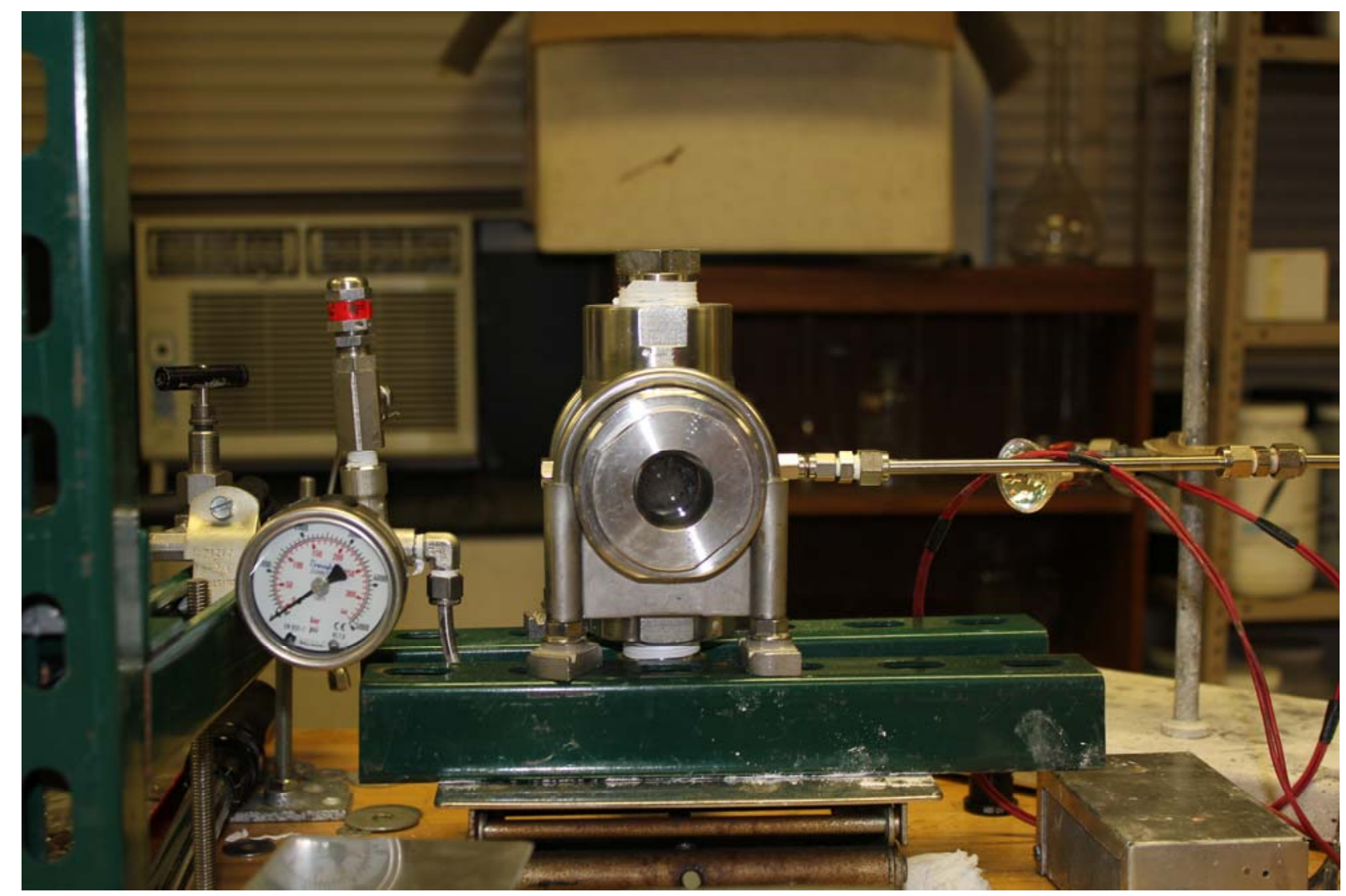

Figure 11. Pressure View Cell 


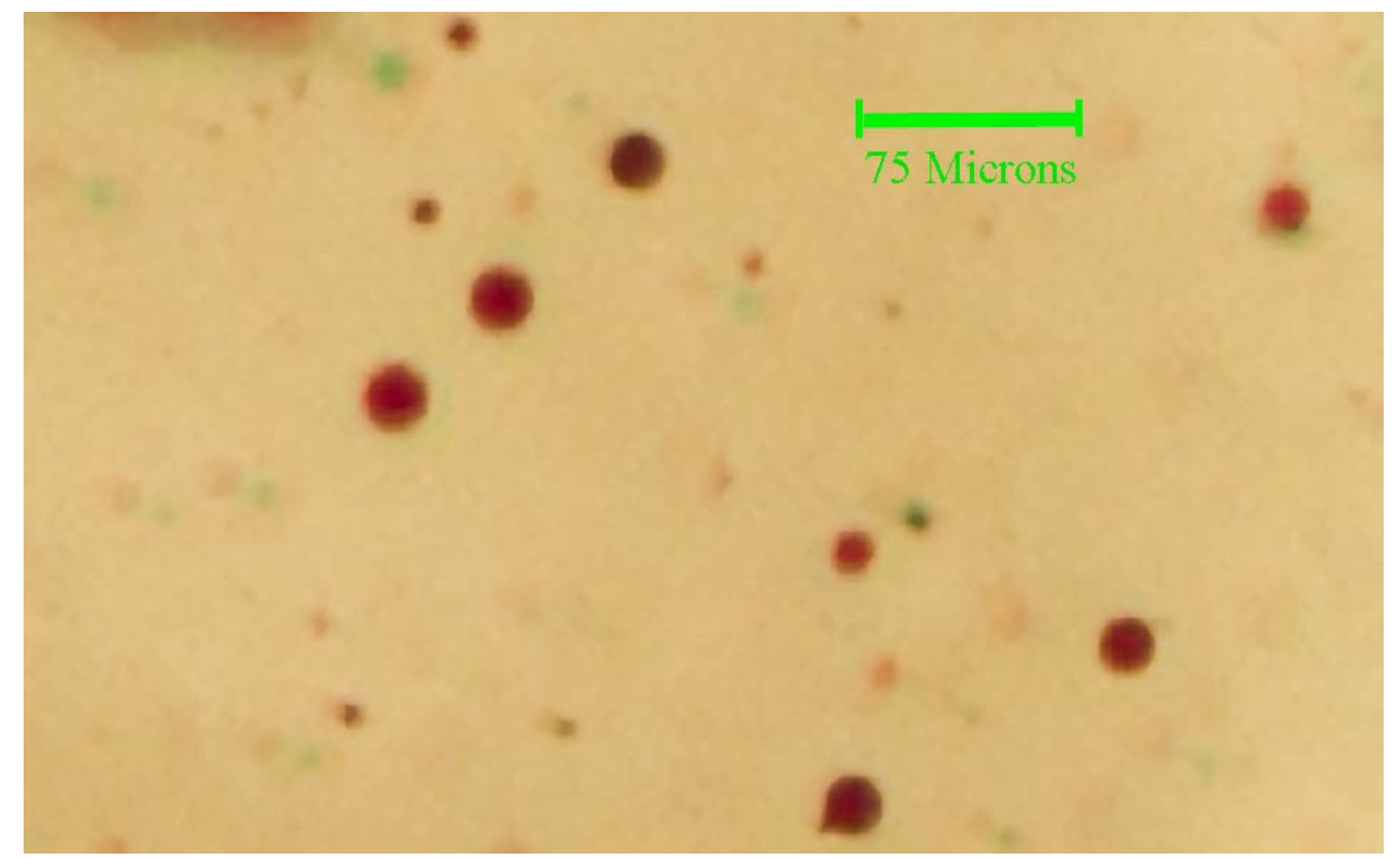

Figure 12. Water-in-Carbon Dioxide Emulsion Stabilized by Carbon Black Particles. Globule Diameter $20-30 \mu \mathrm{m}$. 


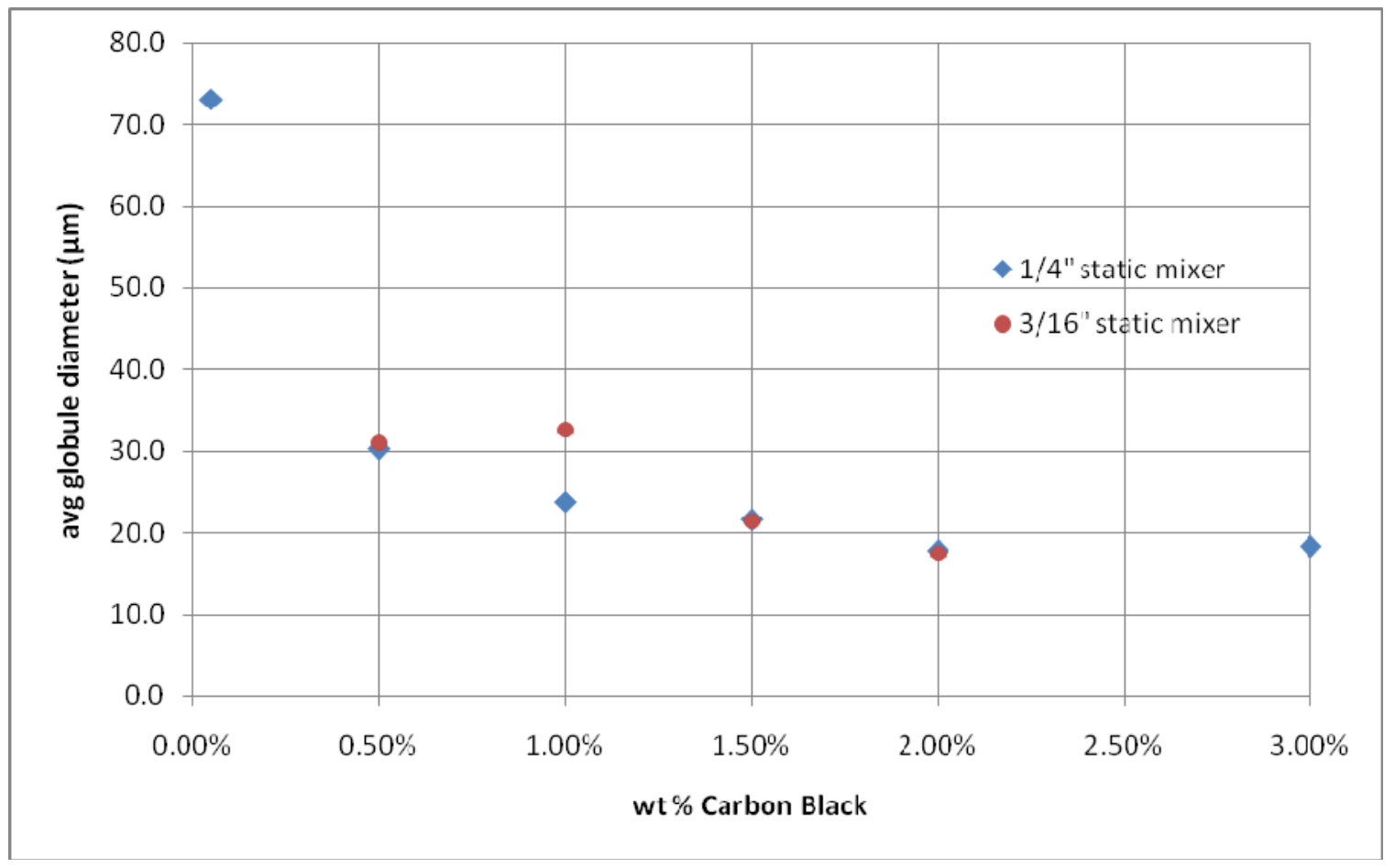

Figure 13. Globule Diameter vs. Carbon Black Concentration in Emulsion. 


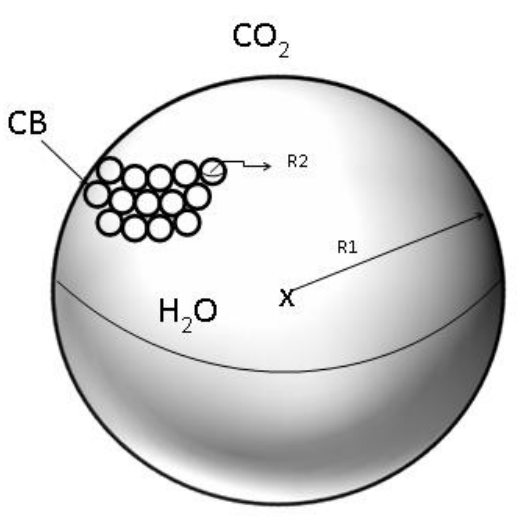

Figure 14. Globule Schematic 


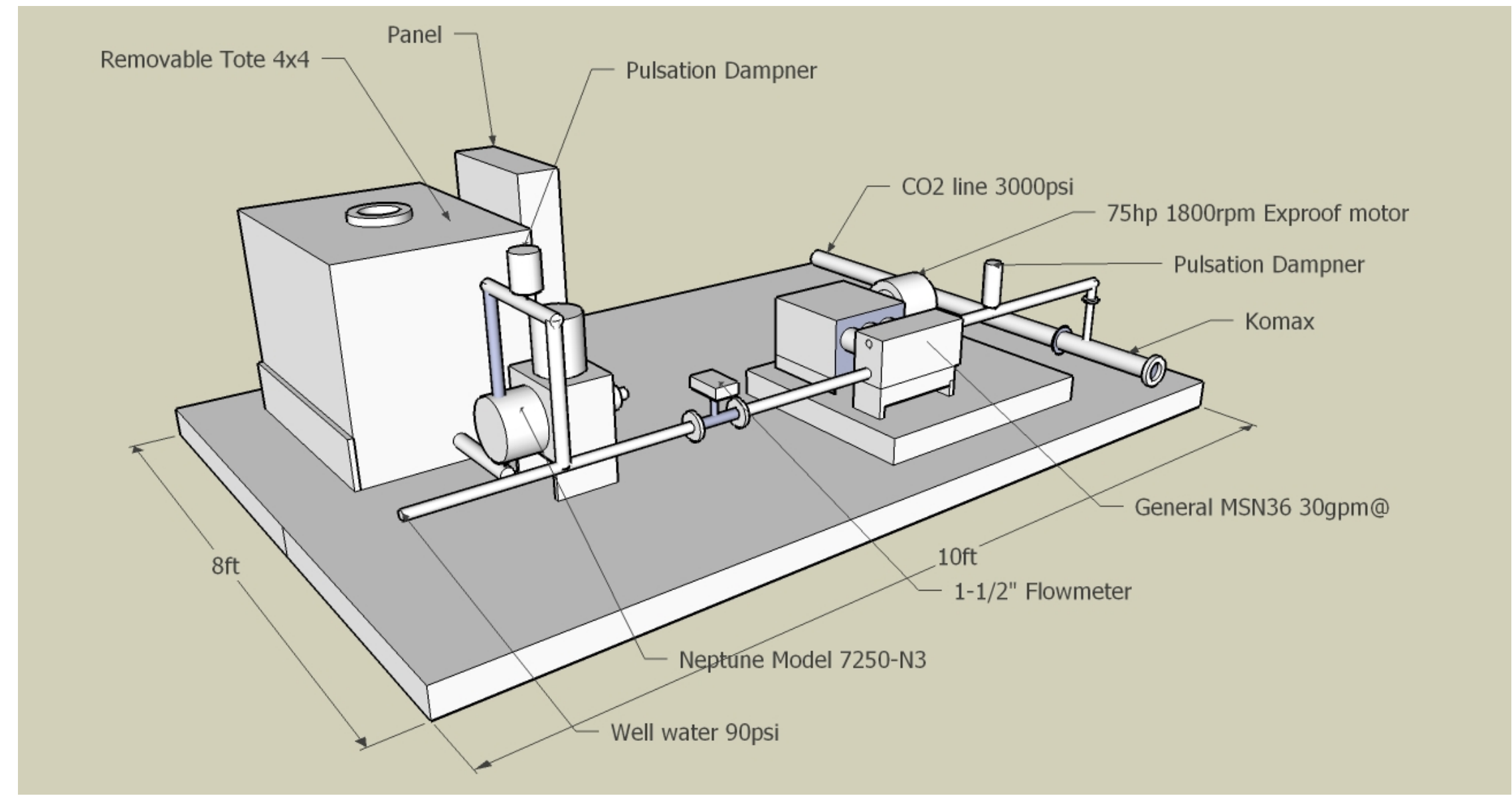

Figure 15. Detailed Design of Scaled Up Emulsion Forming Apparatus with Static Mixer for Field Deployment and Testing. 
Figure 16: Snapshot of Scale-up Design Calculator.

\begin{tabular}{l|l|} 
INPUT: & \multicolumn{1}{l|}{$\begin{array}{l}\text { Fluid } \\
\text { Name: }\end{array}$} \\
Flow (gal/min): & W/C PSE \\
\hline Density (lb/ft ${ }^{3}$ ) & 100 \\
Viscosity (cP): & 37.44 \\
\hline roughness (ft): & 0.1 \\
\hline Piping Length (ft): & 0.00015 \\
\hline
\end{tabular}

OUTPUT:

\begin{tabular}{lllllll}
$\begin{array}{l}\text { Pipe ID } \\
\text { (in) }\end{array}$ & $\begin{array}{l}\text { Velocity } \\
\text { (ft/s) }\end{array}$ & $\begin{array}{l}\text { Reynolds } \\
\text { Number }\end{array}$ & $\begin{array}{l}\text { pressure } \\
\text { drop }(\mathbf{p s i})\end{array}$ & $\begin{array}{l}\text { (psi) per } \\
\text { 100ft pipe }\end{array}$ & $\begin{array}{l}\text { (pipe) } \\
\left(\mathbf{s}^{-1}\right)\end{array}$ & $\begin{array}{l}\text { mixer) } \\
\left(\mathbf{s}^{-1}\right)\end{array}$ \\
0.5 & 163.20 & $3,788,928$ & 712.4073 & 6 & 0 & 0 \\
& & & & & & 27.072 \\
0.75 & 72.53 & $2,525,952$ & 83.9138 & 839.1377 & 9284.27 & 0 \\
& & & & & & 11750.4 \\
1 & 40.80 & $1,894,464$ & 18.4895 & 184.8954 & 3916.80 & 0 \\
1.25 & 26.11 & $1,515,571$ & 5.7378 & 57.3784 & 2005.40 & 6016.20 \\
1.5 & 18.13 & $1,262,976$ & 2.2107 & 22.1073 & 1160.53 & 3481.60 \\
2 & 10.20 & 947,232 & 0.4933 & 4.9333 & 489.60 & 1468.80 \\
2.5 & 6.53 & 757,786 & 0.1549 & 1.5492 & 250.68 & 752.03 \\
3 & 4.53 & 631,488 & 0.0604 & 0.6038 & 145.07 & 435.20 \\
3.5 & 3.33 & 541,275 & 0.0273 & 0.2732 & 91.35 & 274.06 \\
4 & 2.55 & 473,616 & 0.0138 & 0.1378 & 61.20 & 183.60 \\
6 & 1.13 & 315,744 & 0.0018 & 0.0176 & 18.13 & 54.40 \\
8 & 0.64 & 236,808 & 0.0004 & 0.0042 & 7.65 & 22.95 \\
10 & 0.41 & 189,446 & 0.0001 & 0.0014 & 3.92 & 11.75 \\
12 & 0.28 & 157,872 & 0.0001 & 0.0006 & 2.27 & 6.80 \\
14 & 0.21 & 135,319 & 0.0000 & 0.0003 & 1.43 & 4.28 \\
16 & 0.16 & 118,404 & 0.0000 & 0.0001 & 0.96 & 2.87 \\
18 & 0.13 & 105,248 & 0.0000 & 0.0001 & 0.67 & 2.01 \\
20 & 0.10 & 94,723 & 0.0000 & 0.0000 & 0.49 & 1.47 \\
22 & 0.08 & 86,112 & 0.0000 & 0.0000 & 0.37 & 1.10 \\
24 & 0.07 & 78,936 & 0.0000 & 0.0000 & 0.28 & 0.85 \\
& & & & & & \\
\hline
\end{tabular}




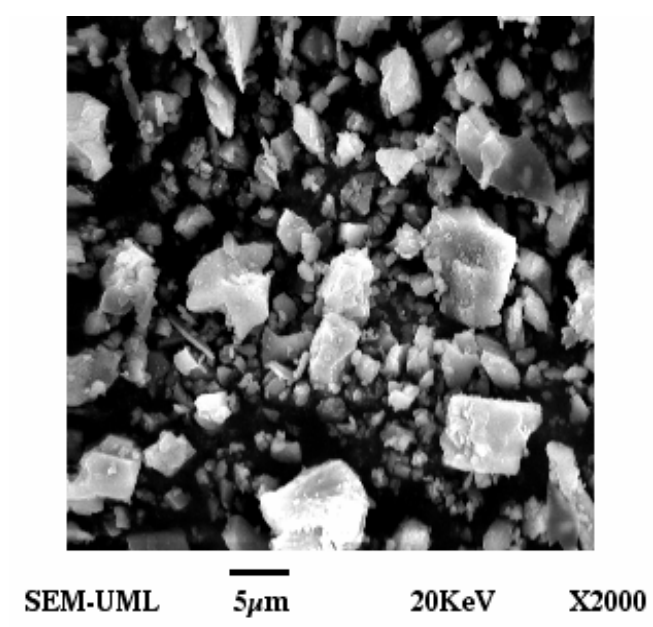

Figure 17. Scanning Electron Micrograph (SEM) of Huber Engineered Materials Hubercarb Q6. 




Figure 18. Schematic of revised emulsion preparation apparatus with static mixer. 


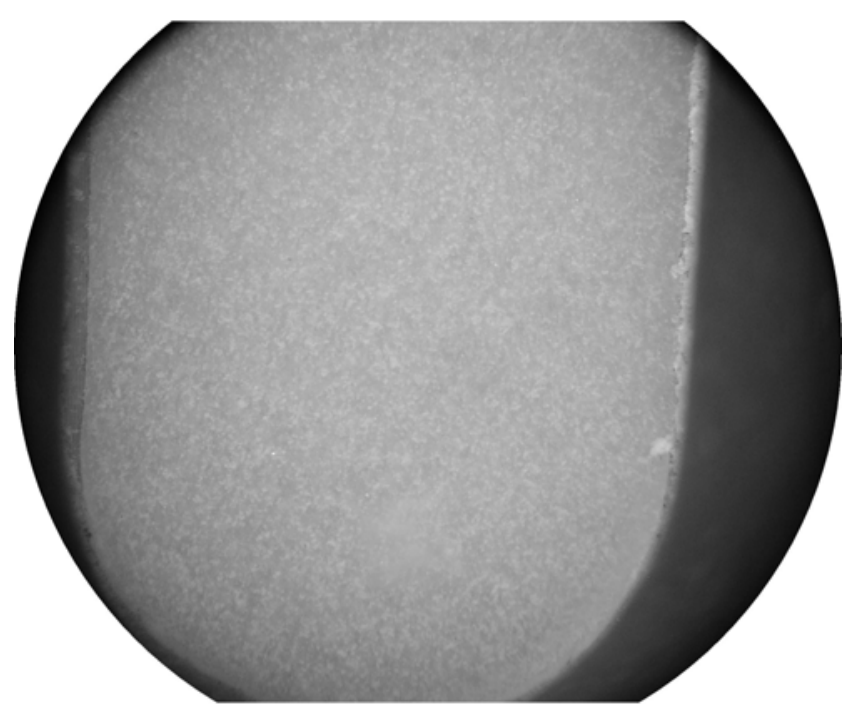

Figure 19. $\mathrm{CO}_{2}-\mathrm{H}_{2} \mathrm{O}$ emulsion stabilized with Hubercarb Q6 calcite particles. Globule diameter in the $70-100 \mu \mathrm{m}$ range. 


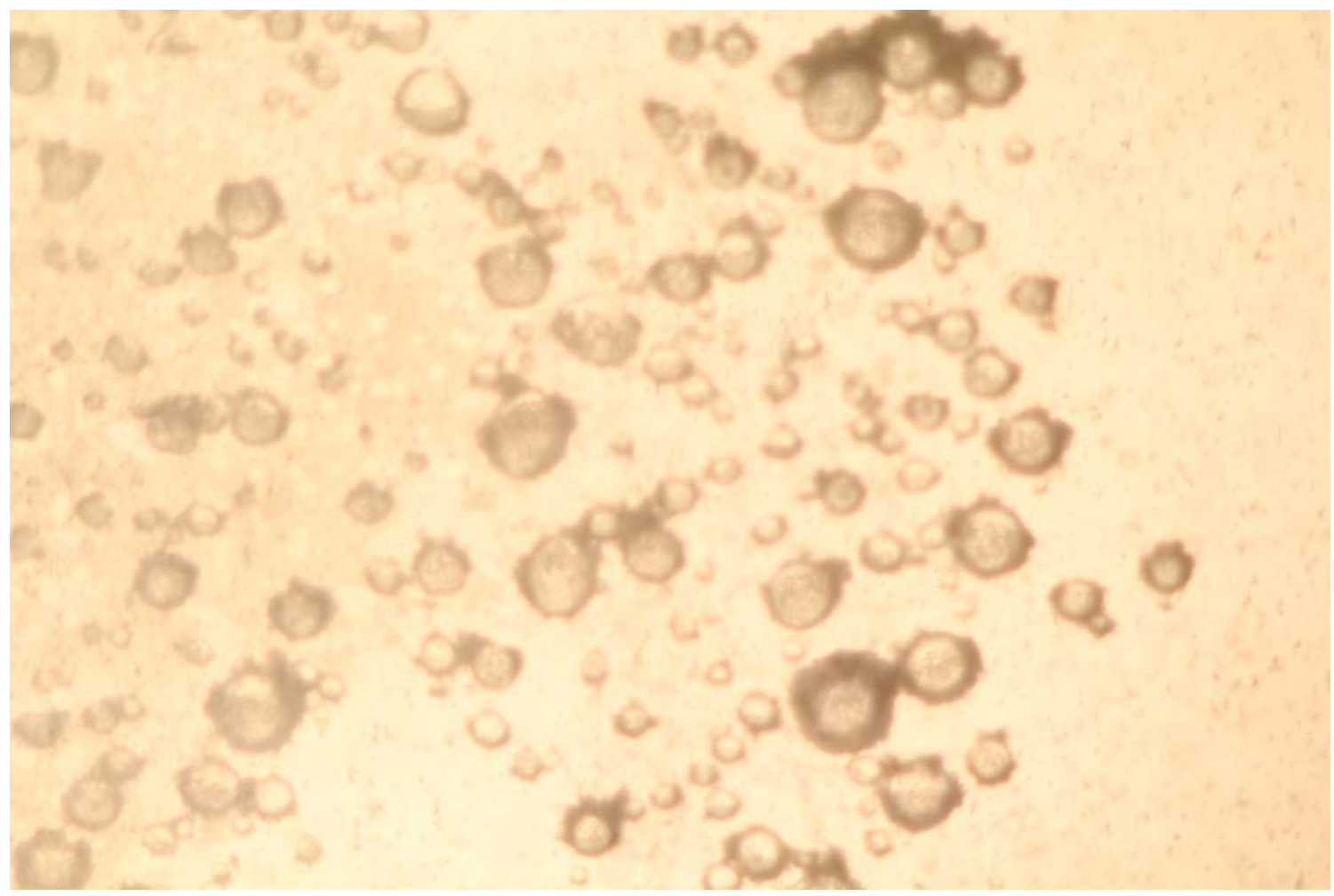

Figure 20. View through window of high pressure cell as approximately $30 \% \mathrm{CO}_{2}$ is mixed with nearly $70 \%$ deionized water through a static mixer with $2 \% \mathrm{CaCO}_{3}$ added as an emulsion stabilizer. 


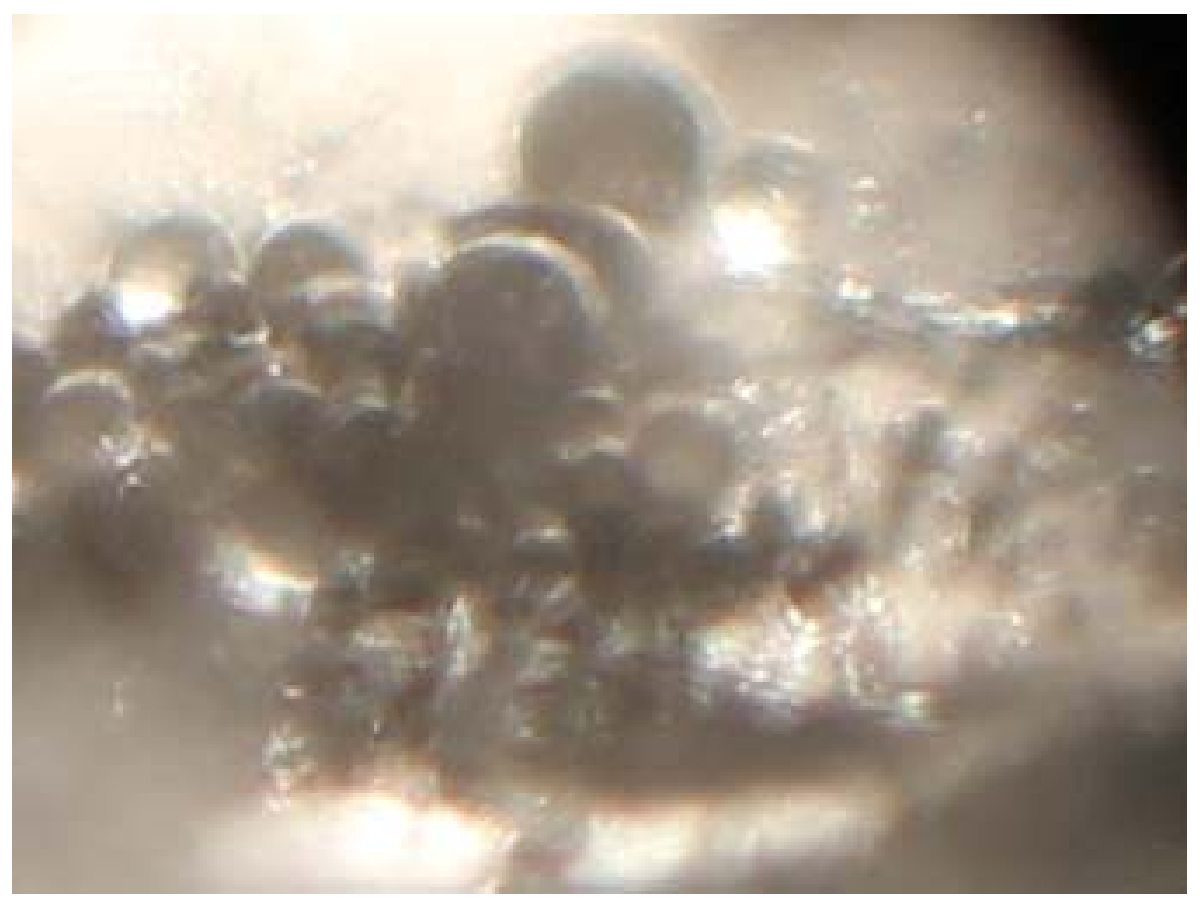

Figure 21. Stopped-flow view of $\mathrm{CO}_{2}$-in-water droplets at lowest concentration of $\mathrm{CaCO}_{3}$ slurry. Droplets have settled to the bottom of the view cell. 


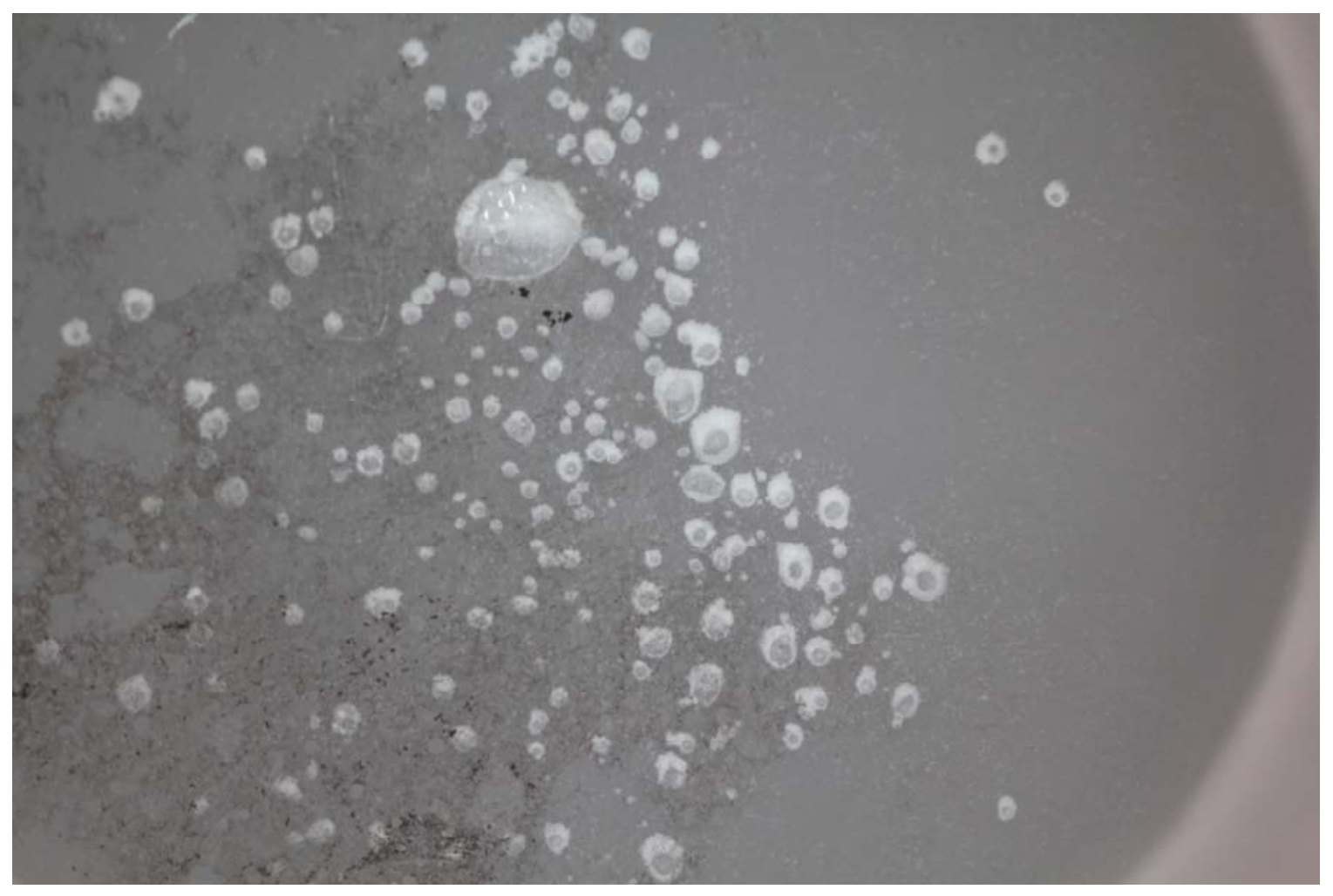

Figure 22. $\mathrm{CO}_{2}$-in-water emulsion at high slurry concentration with other conditions as described above. $\mathrm{CaCO}_{3}$ particles are visible as a thick layer around individual droplets. 